CAMP Working Paper Series

No 2/2012

\title{
What drives oil prices? \\ Emerging versus developed economies.
}

Knut Are Aastveit, Hilde C. Bjørnland and Leif Anders Thorsrud

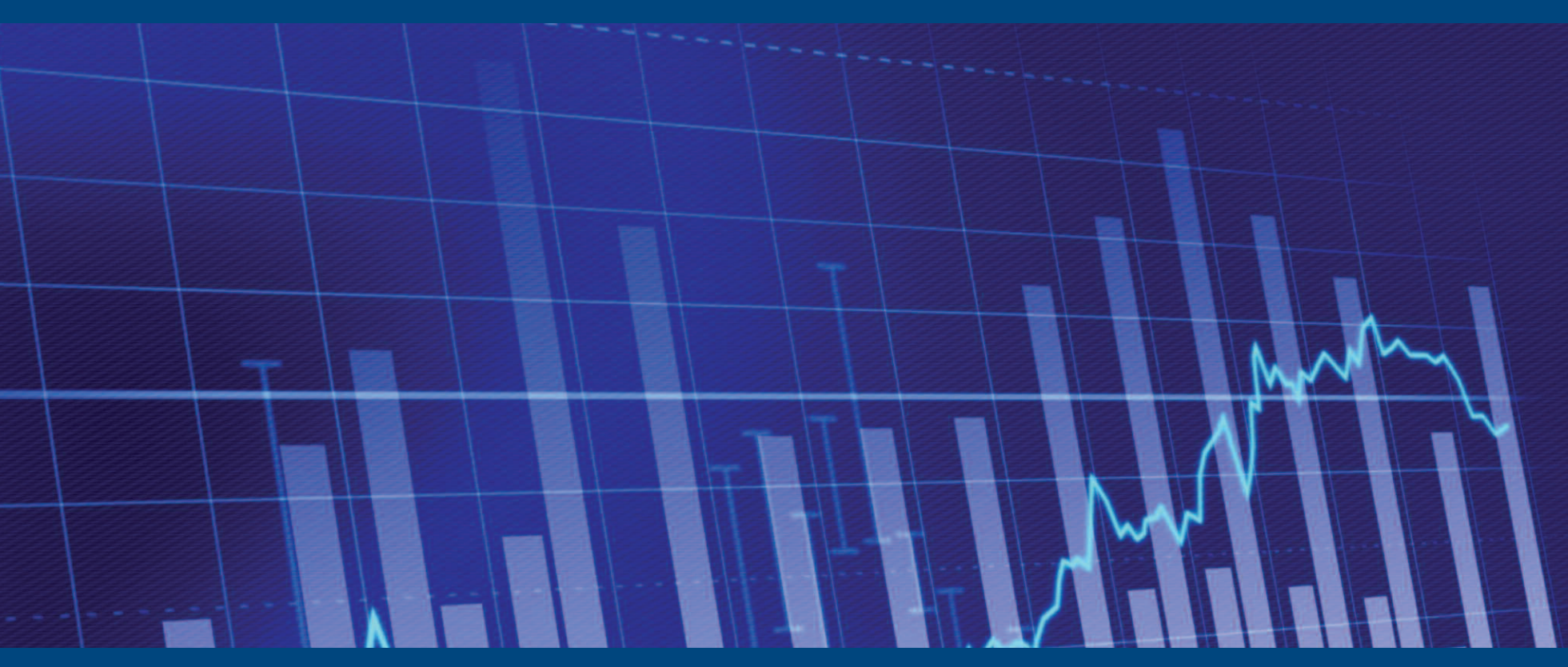

(c) Authors 2012.

This paper can be downloaded without charge from the CAMP website http://www.bi.no/camp 


\title{
What drives oil prices? Emerging versus developed economies*
}

\author{
Knut Are Aastveit ${ }^{\dagger} \quad$ Hilde C. Bjørnland ${ }^{\ddagger}$ \\ Leif Anders Thorsrud ${ }^{\S}$
}

June 16, 2013

\begin{abstract}
This paper explores the role of demand from emerging and developed economies as drivers of the real price of oil. Using a FAVAR model that allows us to identify and compare demand from different groups of countries across the world, we find that demand from emerging economies (most notably from Asian countries) is more than twice as important as demand from developed countries in accounting for the fluctuations in the real price of oil and in oil production. Furthermore, we find that different geographical regions respond differently to adverse oil market shocks that drive up oil prices, with Europe and North America being more negatively affected than emerging economies in Asia and South America. We demonstrate that this heterogeneity in responses is not only attributable to differences in energy intensity in production across regions but also reflects country structures, such as degree of openness and investment share in GDP.
\end{abstract}

JEL-codes: C32, E32, F41

Keywords: Oil prices, emerging and developed countries, demand and supply shocks, factor augmented vector autoregressions

${ }^{*}$ The authors would like to thank Christiane Baumeister, Sandra Eickmeier, James D. Hamilton, Ana Maria Herrera, Lutz Kilian, Francesco Ravazzolo and Benjamin Wong as well as seminar and conference participants at Deutsche Bundesbank, Ghent University, University of Oslo, the American Economic Association 2013 Meeting in San Diego and Norges Bank's conference on 'Modeling and Forecasting Oil Prices' for valuable comments. This paper is part of the research activities at the Centre for Applied Macro and Petroleum economics (CAMP) at the Norwegian Business School. CAMP is supported by Statoil's research program in petroleum economics and The Finance Market Fund of the Research Council of Norway. The usual disclaimer applies. The views expressed in this paper are those of the authors and do not necessarily reflect the views of Norges Bank.

${ }^{\dagger}$ Norges Bank. Email: Knut-Are.Aastveit@norges-bank.no

${ }^{\ddagger}$ Corresponding author: BI Norwegian Business School and Norges Bank. Email: hilde.c.bjornland@bi.no

${ }^{\S}$ BI Norwegian Business School and Norges Bank. Email: leif.a.thorsrud@bi.no 


\section{Introduction}

Since the seminal work by Hamilton (1983), a large body of literature has suggested that there is a significant negative relationship between oil price increases and economic activity in a number of different countries (see, e.g., Burbidge and Harrison (1984), Gisser and Goodwin (1986), Bjørnland (2000) and Hamilton (1996, 2003, 2009) among many others). Higher energy prices typically lead to an increase in production costs and inflation, thereby reducing overall demand, output and trade in the economy.

Most of the research on oil price changes has focused on quantifying the effects on developed countries. The last two decades, the global economic landscape has shifted dramatically. Emerging market economies have experienced rapid growth in economic activity and international trade, outperforming most developed countries across the world. At the same time, the real oil price has more than doubled, without any apparent severe negative effects on the global economy. This has led to an intense research effort to quantify the importance of global demand for the development in the real price of oil, see e.g. Kilian (2009).

This paper breaks ground in the area by explicitly examining the importance of demand from emerging and developed economies as drivers of the real price of oil. Our main focus is to determine if the increased demand for oil originates from emerging economies, which are growing at a pace twice that of the developed economies, or from the developed world, which represents the primary source of demand driving exports and, thus, growth in emerging economies. Having established where demand originates, we analyze how different geographical regions respond to the oil market shocks that drive up oil prices.

To explore these questions, we estimate a factor augmented vector autoregressive (FAVAR) model that includes separate activity factors for emerging and developed economies in addition to global oil production and the real price of oil. The advantage of this modeling strategy is that we can preserve the parsimonious data representation offered by factor modeling techniques, while also including a large cross section of countries and variables in a single model. ${ }^{1}$ Traditionally, empirical studies investigating the interaction between oil prices and the macro economy have employed one or many small-scale vector autoregressions (VAR), typically only including a single country (i.e. Hamilton (1983)) or one index of global activity (i.e. Kilian (2009)) in each model.

${ }^{1}$ The FAVAR model was first introduced by Bernanke et al. (2005) to study the transmission of monetary policy shocks. Other and more recent applications include, e.g., Boivin et al. (2009), Eickmeier et al. (2011), Aastveit et al. (2011) and Thorsrud (2013). 
To differentiate between oil supply and demand shocks, we build on the work of Kilian (2009) which identifies these shocks using recursive zero restrictions in a structural VAR model. Novel to our approach is to utilize a mixture of sign and zero restrictions, which allows us to also identify simultaneous reactions to demand shocks in emerging and developed countries.

Our paper contributes to the large and growing empirical literature investigating the role of demand for oil prices. Barsky and Kilian $(2002,2004)$ first suggested that one should allow for a 'reverse causality' from macroeconomic variables to oil prices. Subsequently, Kilian (2009) has shown that if the increase in the oil price is driven by an increased demand for oil associated with fluctuations in global activity and not disruptions of supply capacity, economic activity may even be positively affected, at least in the short run. Corroborating findings for the US and the Euro area have been documented by Kilian et al. (2009), Kilian and Park (2009), Lippi and Nobili (2012), Peersman and Van Robays (2012) and Aastveit (2013) among others.

We extend the literature in three ways. First, and to the best of our knowledge, this is the first paper to explicitly analyze the contribution of demand from developed and emerging countries on the real price of oil. While it is commonly believed that growth in emerging markets (in Asia in particular) is the main driver of the increased demand for oil (see, e.g., the discussion in Kilian (2009), Baumeister and Peersman (2013) and Hicks and Kilian (2012)), no studies have analysed this question explicitly using a structural model. Therefore, very little is known about the effect that increased growth in emerging economies has had on the real price of oil, and equally important, how economic activity in different regions of the world is affected by the oil market. ${ }^{2}$ Second, the identification strategy adopted to isolate the various demand shocks is novel in the oil literature, as is the use of the FAVAR model for this purpose. Finally, given the large number of countries included in the analysis, this is also the most comprehensive analysis to date of the relationship between oil prices and macroeconomic activity.

We have three main findings, which are robust to numerous robustness checks. First, we show that demand shocks in emerging and developed economies together account for 50-60 percent of the fluctuations in the real price of oil over the last two decades.

Second, demand shocks in emerging markets, particularly in Asia, are more than twice as important as demand shocks in developed economies

\footnotetext{
${ }^{2}$ Hicks and Kilian (2012) show that recent forecast surprises associated with unexpected growth in China and India were central in driving up the real price of oil during the mid 2000s. However, since the forecast errors (i.e. growth in China and India) should be exogenous with respect to the oil market, the study can not analyse the two-way interaction between economic activity and the oil market, which is the focus of our study.
} 
in explaining fluctuations in the real price of oil and global oil production. This is a new finding in the literature. Interestingly, the emerging-market demand shock has by far the strongest effect on Asia, confirming that the Asian countries are the main drivers in the emerging block.

Third, we find that countries respond differently to the adverse oil market shocks that drive up oil prices. In particular, while economic activity in Europe and the US declines substantially following oil supply or oil-specific demand shocks, economic activity in emerging markets in Asia and South America declines by a substantially smaller amount and in some cases actually temporarily increases (at least following oil supply shocks). While some of these results relate to the fact that many emerging countries are commodity exporters that benefit from higher terms of trade, we find that other factors reflecting country structures (such as a high investment share in GDP and a high degree of openness) may be important factors explaining the heterogeneity observed in the responses.

Our results suggest that it is imperative not only to identify where demand is coming from, but also to allow countries to respond differently to various oil market shocks. The puzzling finding in Kilian (2009), where the global real economic activity index actually increases following an adverse oil specific demand shock, could be due to specific features of this index, such as how the data is aggregated and the high correlation between the cost of fuel and the freight index. We eliminate this puzzle by constructing separate emerging and developed activity factors using a FAVAR model.

The remainder of the paper is structured as follows: Section 2 describes the model, the identification strategy and the estimation procedure. We report the results in Section 3. We first describe the estimated factors and their contributions to the domestic variables. Then, we provide a detailed description of the impulse responses of the identified shocks and how they affect changes in the oil price in various historical periods. Section 4 discusses the robustness of the findings, and Section 5 concludes.

\section{Modelling the oil market}

To motivate why we differentiate between developed and emerging countries rather than using an index of global activity, we start by analyzing a three variable structural VAR model that is similar to Kilian (2009). The VAR consists of global oil production (in log differences), an index of global activity (Kilians freight index) and the real price of oil (in logs). Kilian (2009) writes that the global economic activity index he has constructed should capture the component of worldwide real economic activity that drives demand for 
Figure 1: Impulse responses - monthly model

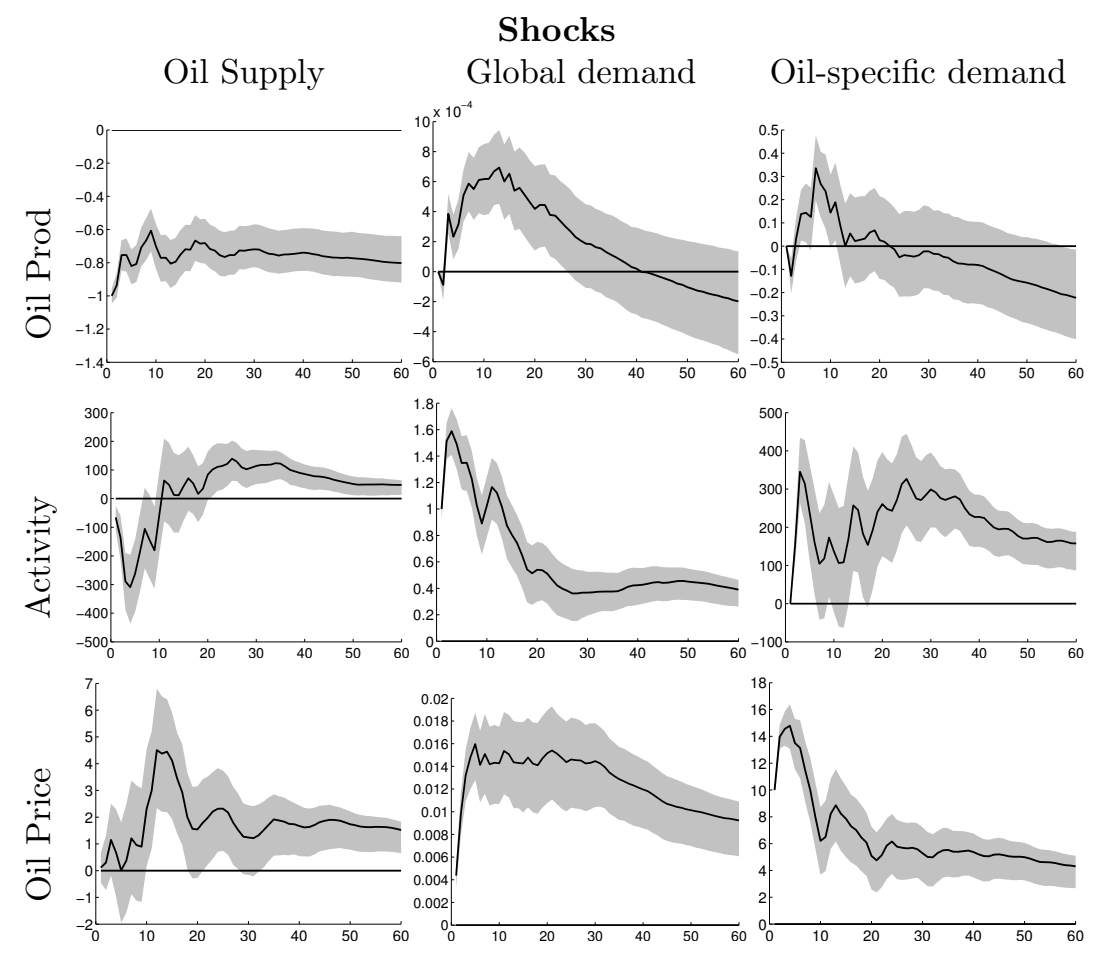

Note: The responses are displayed in levels of the variables. The global demand shock is normalized to increase the activity index by one percent. To facilitate comparison with earlier studies, the oil supply shock is normalized to decrease oil production by one percent, while the oil-specific demand shock is normalized to increase the real oil price by 10 percent. The gray shaded area represent 68 percent confidence bands (bootstrapped), while the black solid lines are the point estimates.

industrial commodities in global markets. ${ }^{3}$ The structural shocks are identified by imposing a recursive ordering. Figure 1 shows impulse responses for the different shocks estimated on monthly data for the sample period used in this paper 1992:M1 to 2009:M12. Note that the sample is shorter than in Kilian (2009) (1973:M1 to 2007:M12), but the responses are qualitatively similar.

The central message in Kilian (2009) is that oil price increases have very different effects on real economic activity depending on the underlying cause of the price increase. This is illustrated in Figure 1. Positive global demand

${ }^{3}$ More precisely, the index is based on representative single-voyage freight rates for various bulk dry cargoes consisting of grain, oil seeds, coal, iron ore, fertilizer, and scrap metal. 
shocks increases the real oil price as well as oil production substantially. On the other hand, if the oil price increase is due to an adverse oil supply shock (that reduces oil production), global activity contracts.

More puzzling, however, is the effect of the adverse oil specific demand shock (right column) that increases both oil prices and global activity significantly (a feature also seen in Kilian (2009)). These results hold whether we use real oil prices in levels or first difference, and whether we use monthly or quarterly data. According to Kilian (2009), the shock is interpreted as a precautionary oil-specific demand shock, ultimately driven by expectations about future oil supply shortfalls. Hence, the shock should have a negative (or at least, non-positive) effect on global activity.

There may be two reasons for this puzzling result. First, the global index is constructed using dry cargo freight rates that may increase with oil price increases (since shipping services uses bunker fuel oil as an input), and not because both are driven by higher demand for commodities. Kilian (2009) argues that by imposing a zero restriction on the impact effect on the global activity index, effectively solves this problem. The responses presented in Figure 1 suggest that this may not be the case, as global activity shows persistently positive effects following an oil specific demand shock.

Second, the contribution of emerging countries to the global index may have increased significantly since China entered into the free trade agreement by WTO i 2001. Hence, the emerging countries could have a large contribution to this index the last 10-15 years. The consequence will then be that if emerging countries also respond less negatively to oil price increases than developed countries (due to different country structures, price elasticities or subsidies), using Kilians freight index in an analysis will underestimate any negative effects an adverse oil price shock can have on the developed world.

We hypothesize that it is imperative not only to identify where demand is coming from, but also to allow countries to respond differently to various shocks. We turn to this below.

\subsection{The Factor Augmented VAR model}

The main purpose of this paper is to study the impact of demand in developed and emerging economies on fluctuations in the real price of oil. To do so, we specify a model that includes separate measures for activity in developed and emerging economies, in addition to global oil production and the real price of oil. The activity measures are intended to capture the respective shifts in the demand for oil in developed and emerging markets and are constructed by applying factor modeling techniques. More precisely, our full model is a FAVAR that builds on the general setup of Bernanke et al. (2005) and Boivin 
et al. (2009).

It is instructive to represent the model in a state space form. Here the transition equation is specified as:

$$
F_{t}=\beta(L) F_{t-1}+u_{t}
$$

where $F_{t}=\left[\begin{array}{llll}\Delta \operatorname{prod}_{t} & \text { devAct } & \text { emeAct } & \Delta r p o_{t}\end{array}\right]^{\prime}$ are the first differences of the logarithm of global oil production, an unobserved developed economy activity factor, an unobserved emerging economy activity factor and the first difference of the logarithm of the real price of oil ${ }^{4}$, respectively. $\beta(L)$ is a conformable lag polynomial of order $p$, and $u_{t}$ is a $4 \times 1$ vector of reduced form residuals. The structural disturbances follow $u_{t}=\Omega^{1 / 2} \varepsilon_{t}$, with $\varepsilon \sim N(0,1)$ and $\Omega=A_{0}\left(A_{0}\right)^{\prime}$, where $\Omega$ is the covariance of the reduced form residuals.

The observation equation of the system is:

$$
X_{t}=\Lambda F_{t}+e_{t}
$$

where $X_{t}=\left[\begin{array}{llll}\Delta \operatorname{prod}_{t} & X_{t}^{\text {dev }} & X_{t}^{\text {eme }} & \Delta r p o_{t}\end{array}\right]^{\prime}$ is a $N \times 1$ vector of observable variables, and $X_{t}^{\text {dev }}$ and $X_{t}^{e m e}$ are $N^{\text {dev }} \times 1$ and $N^{e m e} \times 1$ vectors of developed and emerging activity variables, respectively. $\Lambda$ is a $N \times 4$ matrix of factor loadings, and $e_{t}$ is a $N \times 1$ vector of idiosyncratic, zero mean, disturbances. Below we discuss details on estimation and identification of the FAVAR model.

\subsection{Estimation and model specification}

We estimate the reduced form model (equation (1) and (2)) in a two step procedure: First, the unobserved activity factors for developed and emerging economies are estimated and identified using the principal components method. Prior to estimating the factors, all variables are transformed to induce stationarity, by using the first difference of the logarithm of the respective variable, and standardized. The identified factors are then used as observed variables in a standard VAR framework. The lag length is set to 4, and the VAR residuals pass standard diagnostic tests. ${ }^{5}$ In our baseline model, $N=66$, and we estimate the model over a sample period from 1992:Q1 to

\footnotetext{
${ }^{4}$ Since various stationarity tests indicate that the real price of oil is non-stationary in our sample, we include the first difference of the logarithm of the real price of oil in our model. Note that this differs from Kilian (2009) who use the logarithm of the real price of oil.

${ }^{5}$ As shown in, e.g., Hamilton and Herrera (2004), an overly restrictive lag length can produce misleading results regarding the effects of oil market shocks on the macro economy, while increasing the lag length to over one year has negligible effects.
} 
2009:Q4, yielding $T=72$ observations. $^{6}$

To construct distributions for the impulse response functions, and accurately account for the problem of generated regressors in the second estimation step, we employ a residual bootstrap procedure for the entire system with 5000 replications. ${ }^{7}$

\subsection{Data and Identification}

Our data set includes variables from 33 different countries, where we use real GDP growth and industrial production growth as measures of economic activity for each country, see Appendix A for details. In total, our sample countries account for approximately 80 percent of world GDP, measured by purchasing-power-parity. ${ }^{8}$

We determine a priori which countries should be considered developed and emerging economies. Countries that are members of the OECD at the beginning of our sample are considered developed economies. The remaining countries are considered emerging economies. Accordingly, the following 18 countries are considered developed economies: Australia, Belgium, Canada, Denmark, Finland, France, Germany, Italy, Japan, Luxembourg, Netherlands, New Zealand, Norway, Spain, Sweden, Switzerland, the UK and the US. The following 15 countries are considered emerging economies: Argentina, Brazil, Chile, China, Hong Kong, India, Indonesia, Korea, Malaysia, Mexico, Peru, Singapore, South Africa, Taiwan and Thailand. ${ }^{9}$ Of these countries, four developed countries (Canada, Denmark, Norway and the UK) and four emerging countries (Argentina, Indonesia, Malaysia and Mexico) are net oil exporters over the period (1991-2009). ${ }^{10}$ However, many other countries are commodity producers (i.e., Australia, New Zealand and Peru), where export

\footnotetext{
${ }^{6}$ Bernanke et al. (2005) investigate two different methods for estimating the state space system in equations (1) and (2): a two step procedure and a joint estimation using likelihoodbased Gibbs sampling techniques. They show that the two procedures produce very similar results. In Appendix E we show that this is the case in our application as well. However, the two step procedure is simpler and much less computationally intensive.

${ }^{7}$ Bai and $\mathrm{Ng}$ (2006) show that the least squares estimates obtained from factor-augmented regressions are $\sqrt{T}$ consistent and asymptotically normal if $\sqrt{T} / N \rightarrow 0$. In our sample, this is certainly not the case, and bootstrap methods are thus a potential alternative to the normal approximation, see e.g., Goncalves and Perron (2013). Furthermore, the confidence bands for the impulse response functions are bias adjusted in the sense that we use Hall's percentile intervals (see Hall (1992)).

${ }^{8}$ Authors calculations based on 2009 estimates from the IMF.

${ }^{9}$ Note that Chile, Korea and Mexico are now members of the OECD.

${ }^{10}$ Although Brazil is not a net oil exporter over the entire period, in recent years Brazil has been a major producer and a net exporter.
} 
prices may have been highly correlated with oil prices over the period. See Table 3 in Appendix B for additional information.

To measure oil production and the real price of oil, we use world crude oil production, in millions barrels per day, and the US real refiners acquisition cost of imported crude oil, respectively. The nominal oil price has been deflated using the US consumer price index. These are the same variables used in, e.g., Kilian (2009).

Identification in this model is affected by two issues: First, we need to estimate the unobserved factors such that the developed economy and emerging economy factors are identified, and, second, we need to identify the structural shocks. We turn to each of these issues below.

\subsubsection{Identifying the factors}

As described above, two of the factors in our system are observable, $\Delta \operatorname{prod}_{t}$ and $\Delta r p o_{t}$. Thus, we only need to estimate and identify the two unobserved

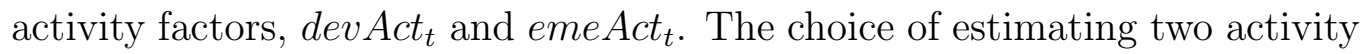
factors is motivated by the economic question we investigate. However, the different information criteria discussed in Bai and $\mathrm{Ng}$ (2002) also suggest that two factors are appropriate for our data set. To obtain unique identification, we follow the method proposed by Bai and $\mathrm{Ng}$ (2013). Here, two unrestricted factors are first estimated using the principal components based on the vector $X_{t}$, defined in equation (2). Then, these factors are organized in the $F_{t}$ vector described above and rotated to ensure that they can respectively be identified as a developed and an emerging activity factor. In particular, we implement the rotational identification restrictions, which Bai and Ng (2013) label PC3, such that $\Lambda^{*}=\left[\begin{array}{ll}I_{r} & \Lambda_{2}\end{array}\right]^{\prime}$, where $I_{r}$ is a $4 \times 4$ identity matrix, and $\Lambda_{2}$ is a $(N-4) \times 4$ loading matrix.

Rewriting the observation equation as:

$$
X=F \Lambda^{\prime}+e,
$$

where $F=\left(F_{1}, F_{2}, \ldots, F_{T}\right)^{\prime}$ is the $T \times r$ matrix of factors and $\Lambda=\left(\lambda_{1}, \lambda_{2}, \ldots, \lambda_{N}\right)^{\prime}$ is the $N \times r$ matrix of factor loadings (with $\lambda_{1}=\left(\lambda_{1,1}, \lambda_{1,2}, \ldots, \lambda_{1, r}\right)^{\prime}$, the identified factors $\left(F^{*}\right)$ and loadings $\left(\Lambda^{*}\right)$ are easily estimated based on the unrestricted estimates $(F$ and $\Lambda)$ as follows: $F^{*}=F \Lambda_{r}^{\prime}$ and $\Lambda^{*}=\Lambda \Lambda_{r}^{-1}$.

The rotation of the initial factor estimates depends on $\Lambda_{r}$, the upper $4 \times 4$ component of $\Lambda$, and thus the ordering of the variables in $X$ (in equation (3)). Therefore, we set the first 4 variables in $X$ to be: $\Delta$ prod, $x^{U S}, x^{C h i n a}$ and $\Delta r p o$, which implies that the identified $\Lambda^{*}$ have factor loadings of one on oil production, US and China GDP, and the price of oil (the observable factors 
also have factor loadings of one for their respective variables in the absence of rotation), respectively. The identified factors and loadings can then be reordered such that they comply with the ordering provided in equations (1) and (2).

Importantly, this identification strategy places no restrictions on the correlations between the factors, but still yields $r^{2}=16$ restrictions, thus ensuring unique identification of the factors and loadings (see Bai and $\mathrm{Ng}$ (2013) for details). In Section 4, we show that our results are robust to alternative choices regarding how we estimate and normalize the factors.

\subsubsection{Identifying the shocks}

To identify the structural shocks in the FAVAR model, we build on the work of Kilian (2009), which differentiates between oil supply and demand shocks in a structural VAR model. The novelty of our study is the identification of separate demand shocks in emerging and developed economies.

Accordingly, to identify the structural innovations in the model as oil supply shocks, developed-country oil demand shocks, emerging-country oil demand shocks and other oil-specific demand shocks, we employ a mixture of sign and zero restrictions, which are novel in this literature. In particular, we restrict $A_{0}$, defined in section 2 as:

$$
\left[\begin{array}{c}
u^{\text {prod }} \\
u^{\text {devAct }} \\
u^{\text {emeAct }} \\
u^{\text {rpo }}
\end{array}\right]=\left[\begin{array}{cccc}
x & 0 & 0 & 0 \\
x & + & + & 0 \\
x & + & + & 0 \\
x & x & x & x
\end{array}\right]\left[\begin{array}{c}
\varepsilon^{\text {oil supply }} \\
\varepsilon^{\text {developed demand }} \\
\varepsilon^{\text {emerging demand }} \\
\varepsilon^{\text {oil-specific demand }}
\end{array}\right]
$$

where + indicates that the effect of the shock must be positive, $x$ leaves the effect unrestricted, and, finally, zero imposes contemporaneous exclusion restrictions.

The identification strategy imposes the following restrictions. First, crude oil supply shocks $\left(\varepsilon_{t}^{\text {oilsupply }}\right)$ are defined as unpredictable innovations to global oil production. The supply shocks are allowed to affect oil production, all activity measures and the price of oil within the quarter, while oil production itself responds to all shocks except the oil supply shock with a lag. This implies a vertical short-run crude oil supply curve. As adjusting oil production is costly, and the state of the crude oil market is uncertain, these are plausible restrictions, (see e.g. discussion in Hamilton (2009) and Kilian (2009)). Baumeister and Peersman (2012) also estimate the price elasticity of oil supply to be very small in our estimation period, consistent with the view that the short-run supply curve is nearly vertical. Note, that in con- 
trast to some of these studies, we use quarterly data instead of monthly data. One could question whether the short-run supply curve is truly vertical for a full quarter. Due to lack of available data at a monthly frequency, we will not be able to check this. However, since the main identifying assumptions used in Kilian (2009) are the same as in our model, we can compare impulse responses from a quarterly version of his model with the original monthly version. The responses are very similar.

Second, innovations to the activity factors for developed and emerging economies (that cannot be explained by global oil supply shocks) are referred to as, respectively, developed-country oil demand shocks ( $\varepsilon^{\text {developed demand }}$ for short) and emerging-country oil demand shocks ( $\varepsilon^{\text {emerging demand }}$ for short). The real price of oil, as well as the developed and the emerging activity factors, can be affected on impact by these demand shocks. As such, we allow for a simultaneous reaction to demand shocks in emerging and developed countries. This is plausible given the relative sizes of the economies (or block of countries) and the potential interaction due to trade and financial integration. At the end of 2009, the emerging and developed economies in our sample accounted for approximately 32 and 47 percent of world GDP based on purchasing-power-parity. Moreover, compared to standard recursive identification, the advantage of our identification strategy is that it is insensitive to whether the developed factor is ordered above the emerging factor or vice versa in the VAR. However, this makes column two and three of the sign restriction matrix equal, and to fully identify the structural shocks, we impose two additional sign restrictions on the short-run impulse responses: To identify $\varepsilon^{\text {developed demand }}$, we impose that the response of devAct - emeAct $>0$, and to identify $\varepsilon^{\text {emerging demand }}$ we impose that the response of emeAct - devAct $>0$. The restriction implies that after an emerging-country demand shock (that increases activity in emerging countries), activity in developed countries is also restricted to increase, but by less than in the emerging countries (and vice versa for a developed-country demand shock). This type of restriction allows us to identify demand from different groups of countries (regions). ${ }^{11}$ All sign restrictions are set to hold for 2 quarters only. The results are robust to altering the horizon by one quarter.

Finally, other innovations to the real price of oil that cannot be explained by $\varepsilon^{\text {oil supply }}, \varepsilon^{\text {developed demand }}$ or $\varepsilon^{\text {emerging demand }}$ are referred to as oil-specific demand shocks ( $\left.\varepsilon^{\text {oil-specific demand }}\right)$. Although this shock captures all other oil

${ }^{11}$ Restrictions on one variable relative to another have been applied previously by, among others, Farrant and Peersman (2006) and Eickmeier and Ng (2011) but in a very different context. 
market specific shocks not explained by the other shocks in the model, Kilian (2009) argues that such a shock primarily captures precautionary demand for oil driven by the uncertain availability (scarcity) of future oil supply.

With minor modifications, the sign restrictions are implemented following the procedure outlined in Rubio-Ramirez et al. (2010) and Mumtaz and Surico (2009) and is explained in detail in Appendix D.

As is now well known in the literature, the sign restrictions will not yield unique identification (see Fry and Pagan (2011)). That is, while the sign restrictions solve the structural identification problem by providing sufficient information to identify the structural parameters, there will be many models with identified parameters that provide the same fit to the data. Accordingly, the (median) estimated impulse response functions potentially represent responses to shocks from different models, implying that the structural shocks may not be orthogonal.

To circumvent this problem, we follow Fry and Pagan (2011) and adopt the following procedure: For each set of reduced form parameters, we draw 1000 accepted candidate impulse responses (based on $A_{0}$ above), and compute the mean impulse response function among these accepted draws. We then compute the mean squared error between all candidate functions and the mean impulse response function. The impulse response function with the lowest score is stored. As such, for each set of parameter estimates, the identified structural shocks are orthogonal.

\section{Results}

In the following, we first present the oil variables and the identified activity factors for developed and emerging economies. Next, we investigate what drives the real price of oil and oil production, and finally we examine how the different regions and countries are affected by the adverse oil market shocks; oil supply and oil-specific demand shocks.

\subsection{Factors}

Figure 2, panels (a) and (b), displays the two observable series: global oil production and the real price of oil. The figure (Panel (a)) shows significant growth in the real price of oil during the economic booms in 1999/2000 and 2006/2007 and a decrease in the real price of oil during the Asian crisis and the recent financial crisis. The economic booms and busts are also evident in global oil production (Panel (b)), where production slows during the two recessions and increases during the two expansions. Furthermore, there is 
Figure 2: Observable variables and estimated factors

(a) Real oil price

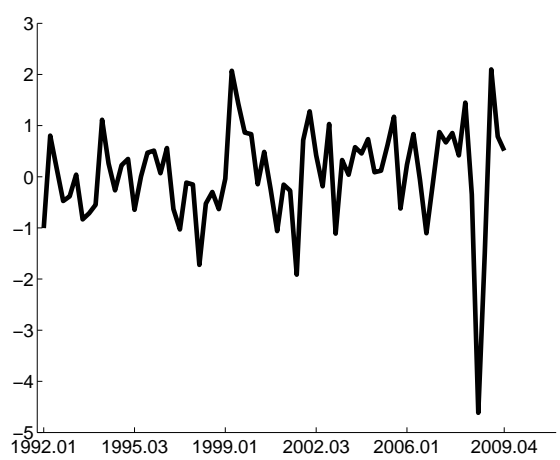

(c) Emerging activity

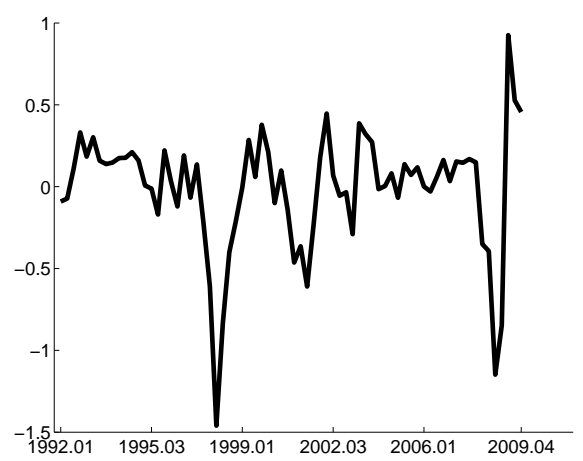

(b) Oil production

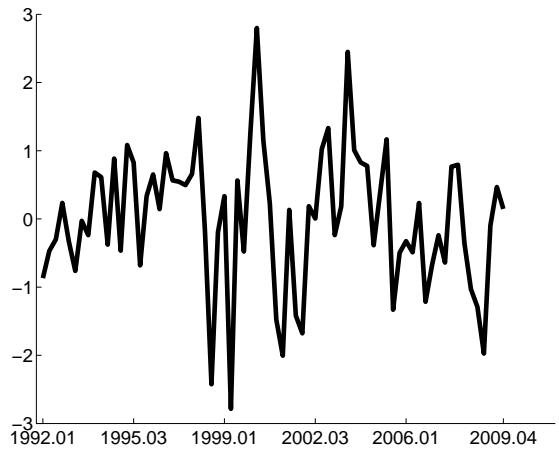

(d) Developed activity

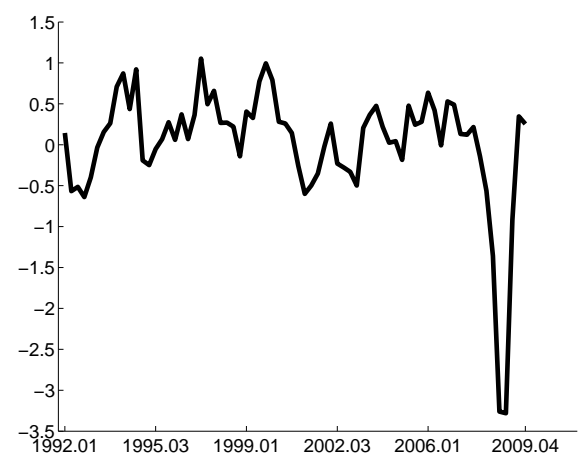

Note: The figure shows the standardized values of the first differences of the logs of each observable variable, i.e. the real price of oil and global oil production, and the estimated activity factors (the median). The sample used in the VAR is 1992:Q1 to 2009:Q4, while we use information from 1991:Q1 to 2009:Q4 to estimate the unobserved factors.

also evidence of a slowdown in global oil production during 2002/2003. The dates coincide with the Venezuelan unrest (strike) and US attack on Iraq (second Persian Gulf War).

Figure 2, panels (c) and (d), displays the two key activity variables used in the analysis: Emerging and developed economy factors. As the figure shows, the two factors capture features commonly associated with the business cycles in each region over the last 20 years. Both the booms and busts predating and following the Asian crisis near the end of the 1990s, and the dot com bubble around 2001 are evident in the emerging and the developed factors, respectively.

There is, however, a notable difference in how the recent financial crisis 
has affected the two factors. The decline in the activity factor representing the developed economies is much larger than any other previous decline in that factor. For the emerging activity factor, the recent financial crisis also caused large negative movements. However, compared to earlier downturns, the recent crisis does not seem particularly different. Additionally, the recovery in the emerging activity factor has been stronger than in the developed economy factor.

Although the factors should capture common movements among the countries in each group, the various countries may still have different contributions to the factors. In particular, some countries may be more correlated with their respective factor than others. To illustrate this (and to further interpret the factors), Table 3 in Appendix B displays the correlation between the activity variables in each country and the developed and emerging factors. First, regarding the developed factor, the table indicates that with the exception of Australia, Japan, New Zealand and Norway, all developed countries are highly correlated with the developed factor (as expected). For Japan and New Zealand, however, the correlation with the emerging factor (that contains many Asian countries) is slightly higher than with the developed factors. Clearly, location is important. For Norway, and to some extent Australia, the correlation between GDP and either the developed or the emerging factors is low, suggesting a more idiosyncratic pattern in these countries.

Regarding the emerging factor, the results for the Asian and the South American countries are more diverse. While the Asian countries are highly correlated with the emerging factor, three of the South American countries (Argentina, Chile, Mexico) and South Africa are slightly more correlated with the developed factor than with the emerging factor. This indicates that the Asian countries account for the majority of variation in the emerging factor.

\subsection{What drives oil prices?}

Figure 3 reports the impulse responses in the model. Each row contains the responses of the level of a specific variable to the four different shocks. To compare the developed-country and emerging-country demand shocks, we normalize both shocks to increase activity in their respective regions by one percent. The oil supply shock is normalized to decrease oil production by one percent, while the oil-specific demand shock is normalized to increase the real oil price by an initial 10 percent. While the normalization of the two demand shocks allows us to compare the contributions of developed and emerging countries, the normalization of the two 'oil market' shocks is 
selected to facilitate comparison with previous studies.

Beginning with our focal question, what drives oil prices?, we examine the bottom row. While demand in both the developed and emerging countries increases the real oil price significantly for 1-2 years, the effect of the normalized emerging-country demand shock is by far strongest of the two demand shocks (increasing oil prices by an initial 20 percent versus 10 percent for the developed-country demand shock). Interestingly, a shock to the emerging activity factor also has the strongest effect on oil production (upper row), which increases significantly for a year. While demand in developed economies also increases oil production, the effect is not significant.

Next, we present our results on the explanatory power of the two oil market (oil supply and oil-specific demand) shocks. A one percent disruption in oil production due to an oil supply shock eventually increases the oil price by 5-10 percent. The delayed response may reflect that oil deliveries are based on future contracts. Hence, it might take some time before supply disruptions affect prices. Similar delayed responses were also seen in a monthly version of Kilian (2009) estimated on our sample and presented in Figure 1 above.

The last shock, interpreted in Kilian (2009) as a precautionary oil-specific demand shock (ultimately driven by expectations about future oil supply shortfalls), triggers an immediate and sharp increase in the real price of oil (normalized to increase by 10 percent). Such expectations can change almost immediately in response to, e.g., exogenous political events, and therefore tend to increase prices without any subsequent effects on oil production.

Turning to the reverse causality, we ask, what are the effects of the two oil market shocks on the macro economy? First, a disruption in oil production of one percent that eventually increases the real oil price by 5 10 percent reduces activity in developed economies by approximately 0.5 percent (second row in Figure 3 ). However, the same shock causes activity in emerging countries to increase, although the standard error bands are wide (third row). These results are different from Kilian (2009), which finds that global (aggregate) real economic activity falls systematically following oil supply shocks. We will turn to possible reasons for the divergence between emerging and developed countries below. 
Figure 3: Impulse responses

Shocks

Oil supply Developed demand

Emerging demand Oil-specific demand
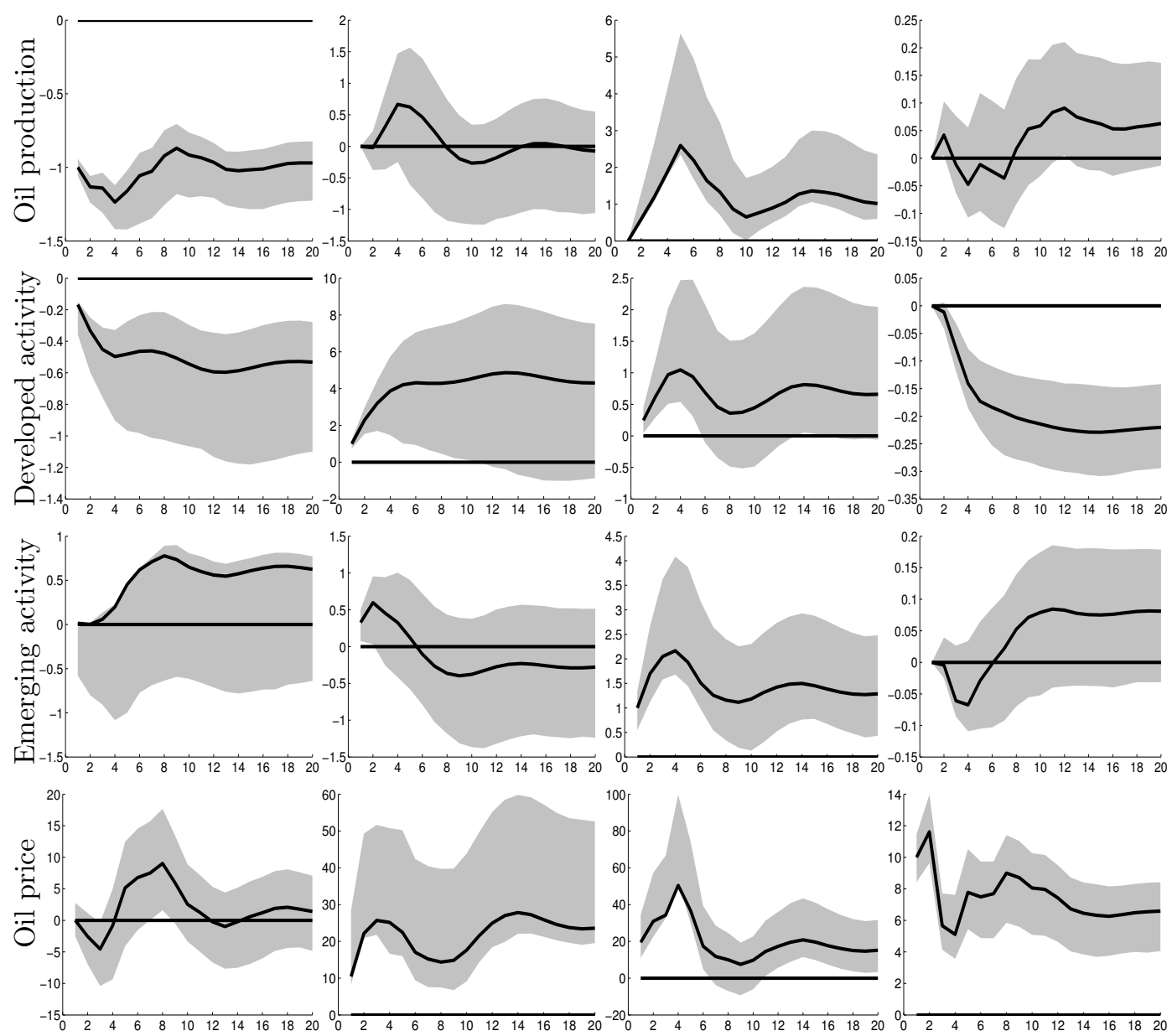

Note: The responses are displayed in levels of the variables. The developed-country and emerging-country demand shocks are normalized to increase activity in developed and emerging countries by one percent, respectively. To facilitate comparison with earlier studies, the oil supply shock is normalized to decrease oil production by one percent, while the oil-specific demand shock is normalized to increase the real oil price by 10 percent. The gray shaded area represent 68 percent confidence bands (bootstrapped), while the black solid lines are the point estimates.

A shock to oil-specific demand, normalized to increase the real price of oil by an initial 10 percent, slightly reduces GDP in the developed countries $(0.2$ percent), while GDP in emerging countries initially declines, then increases 
marginally. ${ }^{12}$ Again, these results are different from Kilian (2009), which finds that global real economic activity actually increases after an oil-specific demand shock. Considering that we found different responses between developed and emerging countries to such a shock (Figure 3), it is conceivable that separating emerging from developed countries when analyzing the effects of oil market shocks on economic activity is also important.

Variance decompositions for the real price of oil and oil production, displayed in panels (a) and (b), respectively, in Figure 4 allow us to compare the relative contributions of all shocks. The figure confirms the results found above. The emerging activity factor is far more important than the developed activity factor in explaining variance in the oil price and oil production. In fact, for 1-2 years, approximately 40 percent of the variation in the oil price is explained by emerging demand shocks, while developed demand shocks explain approximately 15 percent. Turning to oil production, 40-50 percent of the variation is explained by emerging demand shocks, while less than 10 percent is due to developed demand shocks. Therefore, we conclude that demand in emerging countries is more than twice as important as demand in developed economies in explaining the variance in the oil price and up to five times more important in explaining the variance in oil production.

Our results suggest that the emerging countries have higher income elasticity than the developed countries. Typically, as a country becomes more developed (richer), the growth in petroleum use declines (as the country produces less manufacturing goods and more services), and hence income elasticity also declines. Indeed, in our sample, we find that emerging countries in Asia and South America have income elasticities close to unity, while the average across developed countries is approximately 0.5. Consistent with this, Hamilton (2009) has suggested that while the income elasticity of oil consumption in the US has declined over time (to 0.5), the income elasticity in newly industrialized countries may (still) be closer to unity.

Turning to the oil supply shocks, Figure 4, Panel (b), shows that these shocks explain a small share of the variation in the real price of oil. This is consistent with findings in Baumeister and Peersman (2013), who use a time-varying SVAR approach to demonstrate that oil supply shocks have become a less important source of oil price movements in recent years. That oil supply shocks explain a small amount of the variation in the real price of oil in our sample is therefore as expected, and not unique to our study.

Finally, the oil-specific demand shocks explain the remaining 40-50 per-

\footnotetext{
12 Following both an oil supply and an oil-specific demand shock, the uncertainty bands around the responses in the emerging activity factor are particularly large. This could reflect that the emerging market economies are less homogenous than the developed economies, as observed in the correlation numbers reported in Table 3 in Appendix B.
} 
Figure 4: Variance decomposition

(a) Oil price

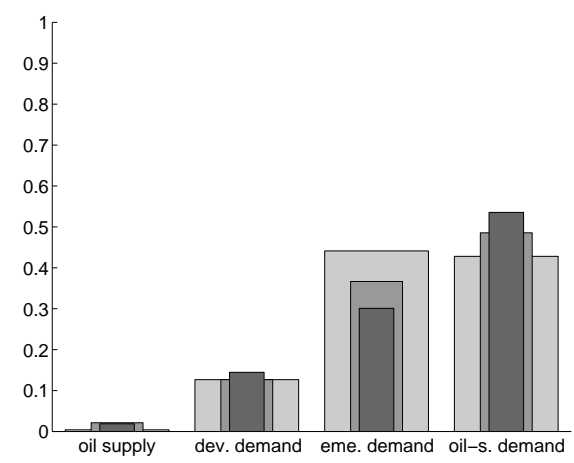

(b) Oil production

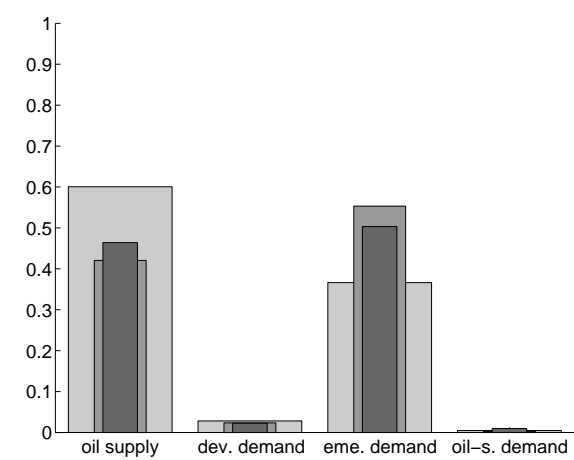

Note: The bars display the variance decomposition with respect to the shocks for horizons 4, 8 and 12 quarters. The widest bars correspond to the shorter horizon.

cent of the variation in the real price of oil after 1-2 years, but a negligible share of oil production at all horizons.

The results in Figure 4 reflect the average contributions of the various shocks over the last two decades. To examine the different periods in greater detail, Figure 5 plots the accumulated contribution of each structural shock to the real price of oil based on a historical decomposition of the data. In particular, Panel (a) shows for each quarter from 1992 to 2009, the real price of oil in levels (solid line) and the real price minus the contribution from the emerging market shocks, i.e., what the real price of oil would have been had there been no emerging demand shocks (dotted line). In panels (b), (c) and (d), the dotted line displays the real price of oil minus the respective contributions of demand from developed countries, oil supply shocks and oil-specific demand shocks. ${ }^{13}$

Panel (a) in the figure emphasizes the importance of emerging markets as drivers of the real oil price. This was especially pronounced in the middle of the 1990s and from 2002/2003 and onwards. In fact, demand in emerging markets added approximately 20 dollars to the peak oil price (approximately 55 dollars in real terms) in 2008. Thus, in our sample, the strong positive contribution from emerging economies has been steadily increasing and was only interrupted by the East Asian crisis (1997/1998) and the broader global economic downturn around 2001.

${ }^{13}$ We scale the initial values such that the total variance explained by each structural shock (the bars in Figure 5) is in accordance with the variance decompositions in Table 4. 
Figure 5: Historical shock decompositions

(a) Oil price without emerging demand

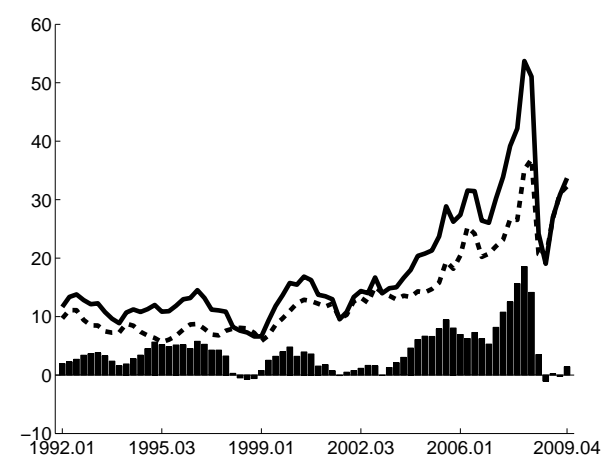

(c) Oil price without oil supply

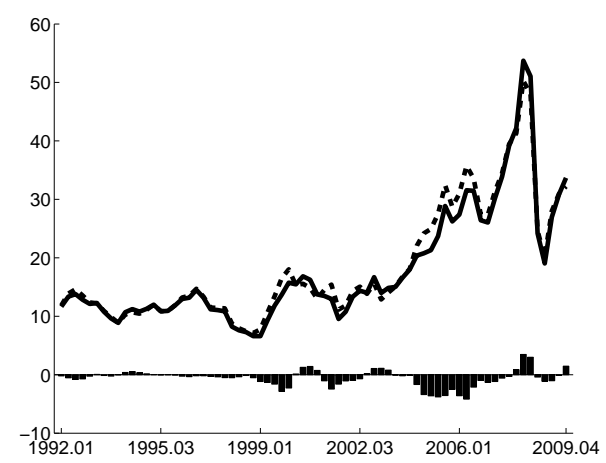

(b) Oil price without developed demand

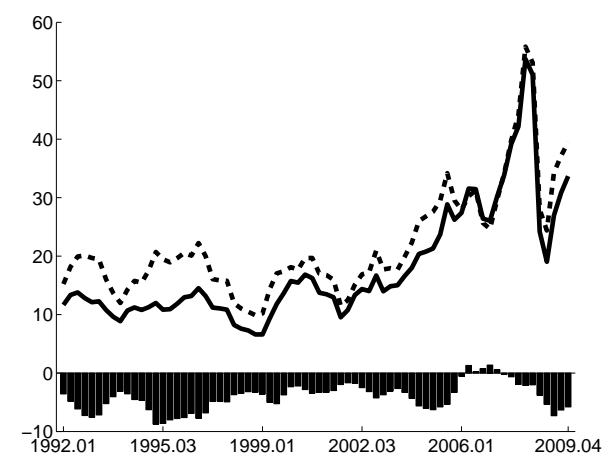

(d) Oil price without oil-specific demand

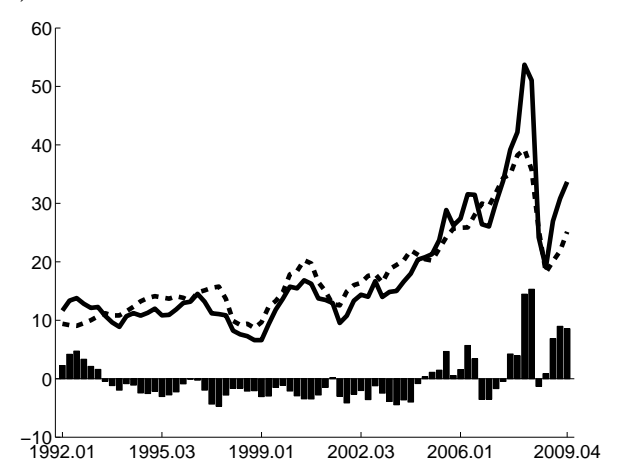

Note: The solid lines display the actual real oil price. The dotted lines display what the oil price would have been if we exclude one of the structural shocks. The bars show the difference between the solid and dotted lines. A positive value indicates that the structural shock contributed to increase the price of oil.

However, demand in developed countries negatively contributed to the real oil price throughout much of the sample period (Panel (b)). Only during the period leading up to the onset of the global financial crisis did developed economies contribute to driving up the oil price. This emphasizes the importance of separating between the various sources behind the demand. While the negative contribution from the developed countries resembles the results for the aggregate global demand shocks identified in Kilian (2009), especially during the 1990s, we show that from 2005 onwards, the positive contribution is primarily due to increased demand from emerging countries.

The contrasting results for emerging and developed economies as driver of the oil price has not been previously documented in the literature, but are 
well in line with the changes in global oil consumption patterns, where, e.g., the share of total world oil consumption attributed to non-OECD countries has grown by approximately 40 percent since the beginning of the 1990s.

The results in Panel (c) reiterate the discussion above; oil supply shocks have contributed little in explaining oil price fluctuations over the last two decades, a finding supported by a number of recent studies. However, as described in, e.g., Hamilton (2013), the only geopolitical events that have potentially affected world oil production since 1992 were the Venezuelan unrest and the second Persian Gulf War, which both occurred around 2003. Although the results in Panel (c) suggest that oil supply shocks increased the price of oil during this period, the effects are small.

Finally, Panel (d), which graphs the historical contribution of oil-specific demand shocks, reveals a more erratic pattern than any of the other shocks. This is consistent with the interpretation that the shock primarily captures precautionary demand for oil, driven by the uncertainty of the future oil supply, as described in Kilian (2009).

\subsection{Region and Country details}

Most recent empirical studies of the interaction between the oil market and the macro economy concentrate on the impact on activity in either one or a few developed (OECD) countries, e.g., the US in Kilian (2009) or France, Germany, Italy, Japan, the UK and the US in Blanchard and Galí (2010). In addition, many studies that assess the impact of oil prices on economic activity across countries only consider net oil importing countries. ${ }^{14}$ Both of these features might limit the generality of the findings.

An advantage of our FAVAR methodology is that we can analyze the responses of various oil and macroeconomic shocks across a large panel of countries. Thus, we add a dimension to the traditional literature discussed above. Below, we investigate the individual country impulse responses provided by the FAVAR framework. For ease of interpretation, we average the responses at different geographical regions in Figure 6 below. That is, Figure 6, panels (a) and (b), displays the average responses in the level of GDP in Asia, Europe, North America (NA) and South America (SA) ${ }^{15}$ to emerging and developed demand shocks respectively, while Figure 6, panels (c) and (d), displays the average responses in the level of GDP in the same regions to oil supply and oil-specific demand shocks respectively. The responses are plotted at a two year horizon, and all shocks are normalized to increase the

${ }^{14}$ Empirical studies by Herrera et al. (2012), Peersman and Van Robays (2012) and Bjørnland $(1998,2000)$ are notable exceptions.

${ }^{15} \mathrm{SA}$ also includes South Africa. 
real price of oil. Note that impulse responses graphing the effect on individual countries' GDPs are displayed in figures 9 and 10 in Appendix C.

A shock to either developed-country or emerging-country demand (normalized to increase activity in each group by one percent initially) has a positive effect on GDP across all geographical regions, see Figure 6. Interestingly, the emerging-country demand shock has by far the strongest effect on Asia, confirming again that the Asian countries are the main drivers in the emerging block. Following a developed-country demand shock, the positive response in Europe is the strongest, followed closely by North America. Of the emerging countries, those in South America are the most positively affected by the developed market shock. This is consistent with observed trade patterns, where a larger share of South America's trade is with developed countries than is the case for Asia.

The responses to the oil supply and the oil-specific demand shocks are more varied. Panel (c) of Figure 6 shows that while economic activity in North America and Europe is negatively affected following an adverse oil supply shock (that increases the real oil price), activity in emerging countries in Asia and South America is much less affected, activity in Asia even increases. Note that although the average response in Asia is substantial, the response is particularly strong in Indonesia and Malaysia, two energy rich countries (see Figure 9 in Appendix C). In South America, only Brazil and Peru respond positively (cf. Figure 9), explaining why the overall response in South America is negative in Figure 6.

The same divergence between the regions can also be found following oilspecific demand shocks, see Panel (d). While all countries are now affected negatively following such an oil shock, the effect is again less severe for the emerging Asian and South American countries than for Europe and the US.

Hence, we have demonstrated that the regions are differentiated, with emerging countries in Asia and South America being more important drivers of the real oil price, yet responding less severely to adverse oil market shocks.

Although these are strong and significant results, a concern could be that the factors might explain very different proportions of the variance in each individual country's activity measure. For example, the correlation between Norwegian GDP and the developed activity factor is only 0.3, while the correlation between US GDP and the developed activity factor is as high as 0.7 (see Table 3 in Appendix B). To avoid a direct dependence on the factor loading structure imposed in the FAVAR, we perform a final exercise where we regress the structural oil supply and oil-specific demand shocks estimated in the model on the individual countries' GDP growth using standard OLS. This also serves as a robustness check for the results plotted in Figure 6 that are based on the regional average of the individual countries' impulse 
Figure 6: Effect of macroeconomic and oil market shocks on GDP in different regions (median)

(a) Emerging demand

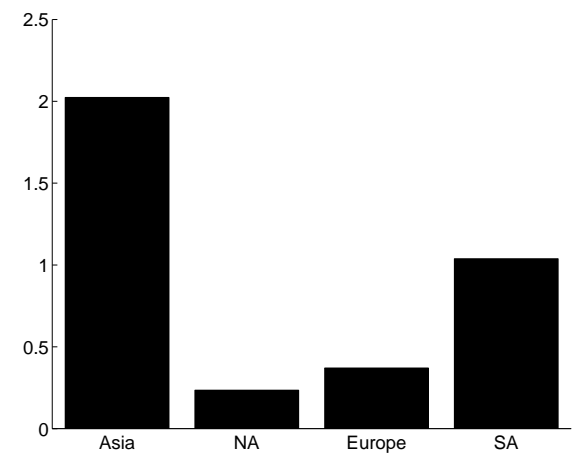

(c) Oil supply

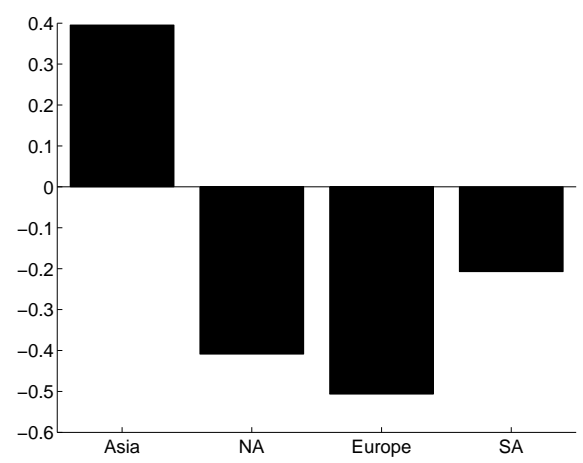

(b) Developed demand

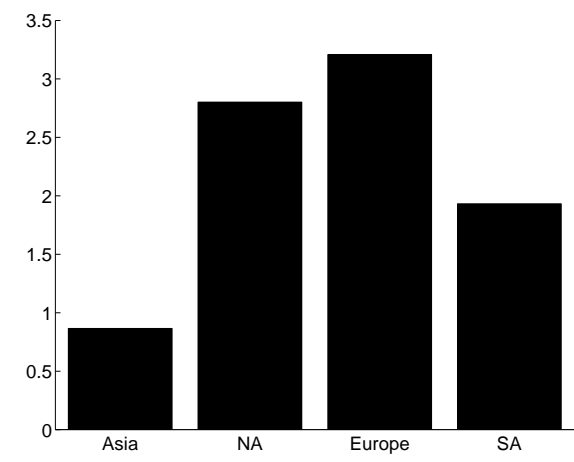

(d) Oil-specific demand

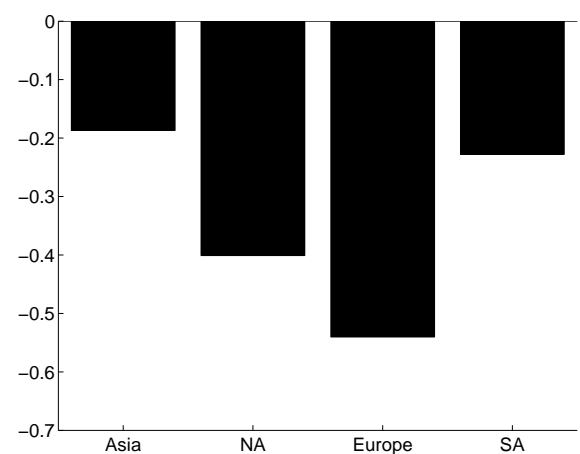

Note: y-axis (vertical axis) measures impulse responses after eight quarters. All shocks are normalized to increase the oil price. See Figure 3 for further details.

responses. The results are plotted in Figure 11 in Appendix C.

The findings confirm the baseline results that oil supply shocks (that temporarily increase the oil price) stimulate GDP in all emerging countries in Asia as well as in Brazil and Peru, while in remaining South America and in the developed countries, GDP instead falls. There are, however, a few exceptions to this picture: In Australia, Germany, New Zealand and Norway, GDP also increases temporarily (as in Asia). While three of these countries are resource rich economies that may actually benefit from a higher commodity price, we need to find other explanations for why economic activity in the remaining Asian countries (and Germany) respond as they do. We will turn to this issue in Section 3.5. 
Regarding the oil-specific demand shock, most countries respond negatively as expected. However, as seen using the FAVAR model above, some Asian countries (most notably Indonesia) respond positively, implying that the average response in Asia is less severe than in the other countries.

\subsection{Comparison with previous studies}

We are unaware of other studies that estimate the effects of oil supply and oil-specific demand shocks on such a large panel of countries that also include emerging countries. It is nonetheless interesting to compare our results to recent studies that analyze the response in the US or a few other developed countries.

First, regarding the size of the responses to an oil supply shock that decreases oil production by one percent, our results (of an eventual increase in the oil price of 5-10 percent and a reduction in GDP in developed economies by 0.5 percent), are slightly stronger than those in, e.g., Kilian and Murphy (2013), and Kilian (2009) but more in line with Baumeister and Peersman (2013), who by applying a time-varying SVAR model for the US, find that for the period we examine, oil supply shocks increase the real price of oil by approximately 10 percent and reduce US GDP by 0.5 percent. The slightly weaker results found in Kilian and Murphy (2013) and Kilian (2009) could be due to differences in sample, but could also relate to the fact that demand is captured by one aggregate global indicator, whereas we separate between demand in emerging and developed countries. Since it is only in the latter group that activity falls significantly following an oil supply shock, separating demand in this way could be important when analysing the interaction between economic activity and the oil market.

Second, the responses to an oil-specific demand shock that is normalized to increase the real price of oil by 10 percent (causing a decline in GDP in developed countries of approximately 0.5 percent) are different from the findings in Kilian (2009), where global real economic activity actually increases after an oil-specific demand shock. This probably reflects that he has not separated developed from emerging countries in the analysis. Instead Kilian (2009) constructs a global real activity index based on representative singlevoyage freight rates (see the discussion in section 2), as discussed above. However, since Asia's demand for commodities has been particularly large the last 1-2 decades, they probably take up a large proportion of this specific index, explaining why global activity responds in line with the emerging countries from our analysis.

Finally, regarding the few studies that distinguish between oil exporting and importing countries, Peersman and Van Robays (2012), analyzing 11 
developed countries, find that following an adverse oil supply shock, economic activity in energy exporting countries such as Norway and Canada temporarily responds positively. Similar results are also found in Bjørnland (1998, 2000). However, while these studies typically attribute this to the fact that countries that respond positively are energy producing countries, we have shown here that there are many energy-importing countries (in Asia in particular) that also behave in this way. Therefore, this is not simply a story of energy intensity in production. We turn to this now.

\subsection{The Asian puzzle - further examination}

The heterogeneity in activity responses across countries and regions to disturbances in the oil market requires further examination. In particular, how is it possible that the emerging activity factor is the main driver of the oil price, yet emerging countries (in Asia in particular) are the least negatively affected by adverse oil supply and oil specific demand shocks? And why do countries such as Australia, Brazil, Germany, New Zealand, Norway and Peru respond in a way that is so similar to the Asian countries?

First, as previously mentioned, some of the countries in the sample are commodity exporters, where the terms of trade increase with higher commodity prices (all of which are in periods highly correlated with the oil price). Australia, Brazil, New Zealand, Norway and Peru are all important exporters of energy, minerals or other raw materials. Some of the Asian countries (Indonesia and Malaysia) also have a high share of net commodity exports in total exports. However, this cannot explain the response in the majority of Asian countries or in Germany. Moreover, as there are other energy exporters that do not respond favorably to oil market shocks (e.g., Argentina and Mexico), there must be other reasons for the observed heterogeneity.

Second, the structure of a country matters. According to Hamilton (2009), a key parameter in determining the consequences of an oil price increase is the share of energy purchases in total expenditures. In particular, a low expenditure share combined with a low price elasticity of demand will imply very small negative effects (if any) of an oil price increase. While the oil consumption share in the US and other industrial economies has generally been flat since the 1980s, it has risen sharply in emerging countries such as China. However, as China began from a much lower level, per capita oil consumption in the US is still 10 times larger than in China (cf. IMF WEO 2011). This may suggest that the (negative) price elasticity in the US is larger (in absolute terms) than in China, and thus that the US and other industrial countries respond more negatively to adverse oil market shocks than emerging countries. 
(a) Correlations between country structure and IRF levels

\begin{tabular}{lccc} 
& Cons & Inv & Open \\
\cline { 2 - 4 } Oil supply & -0.44 & 0.59 & 0.46 \\
Oil demand & $(0.01)$ & $(0.00)$ & $(0.01)$ \\
& -0.28 & 0.48 & 0.22 \\
& $(0.11)$ & $(0.00)$ & $(0.22)$ \\
\hline
\end{tabular}

(b) Regional structure

\section{Emerging Asia \\ Developed countries \\ Emerging South America}

\begin{tabular}{ccc} 
Cons & Inv & Open \\
\hline 55 & 33 & 145 \\
66 & 23 & 60 \\
70 & 22 & 50
\end{tabular}

Note: Cons $=$ consumption, Inv $=$ investment, Open $=$ export+import, all as share of PPP Converted GDP Per Capita at 2005 constant prices. Results are based on the mean of the indicators (over the sample period 1992 - 2009). In Panel (a), the second row for each shock are p-values.

Finally, as pointed out by Edelstein and Kilian (2009) and Hamilton (2009), a key factor transmitting the energy price shocks to the domestic economy has been the automobile sector. In particular, higher energy prices has typically implied an increase in the demand for energy-efficient small cars at the expense of energy-inefficient large cars (SUVs). Consistent with this, Hamilton (2009) has shown that US domestic light truck sales were down almost 30 percent between July 2007 and July 2008 (the year when oil prices peaked), while US import car sales were up 14 percent in the same period. The increased demand in the US for import of energy efficient cars may have benefitted emerging countries in Asia in particular.

In Table 1, we examine these issues in greater detail by analyzing to which extent the composition of output is relevant. In particular, we examine whether countries with a low consumption share and high investment share are less negatively affected by higher oil prices, as investments are less reversible (due to long-term plans) than overall consumption. We also examine if degree of openness is relevant. As discussed above in relation to the mix of industries, countries that has tied most of its capital to the export sector may be able to export some of the increase in oil prices to the importers, 
whose price elasticity may be small.

Panel (a) in Table 1 reports the correlations between the impulse responses from the two oil market shocks, an oil supply shock and an oil-specific demand shock, with the means of the three relevant indicators, the consumption share, investment share and degree of openness over the sample period (1992 - 2009). The table confirms that countries with a high consumption share have negative correlations with the two oil shocks, while countries with high investment shares and degrees of openness will have positive correlations with the oil shocks (oil supply shocks in particular).

Which regions match these features? Table 1, Panel (b), shows that emerging Asia is noteworthy, with a low consumption share, high investment share and a high degree of openness. For South American countries, however, the picture is reversed (high consumption shares, low investment shares and low degrees of openness), which may explain why despite being positively affected by increased terms of trade, they do not respond positively overall.

On a final comment, subsidies may obviously also play a role. Price controls prevent the full cost of a higher imported oil price from being passed through to the end user, thereby dampening the responsiveness of consumption to increases in prices. Studies in the IMF's World Economic Outlook reports from 1999 and 2009 show that pervasive under-pricing of energy resources occurs in several non-OECD countries, including China, India, Indonesia and South Africa. This may also help to explain the small (and occasionally positive) effects of oil supply and oil demand shocks in these countries. We leave this issue to be explored further in another study.

\section{Robustness}

We repeatedly argued that the main drivers of the emerging economies factor are the emerging Asian countries. In this section, we perform an additional exercise that examines the robustness of this finding and examines whether Asia or South America (or a combination of both) drives the relationships between the oil-market and the macro economy presented in Section 3. To do so, we split the sample of emerging countries into two blocks and estimate two different factors: one consisting of emerging Asian countries and one consisting of emerging South American countries (including South Africa). Then, we sequentially use these new factor estimates in our main model, as a replacement for the original emerging economies factor. The results using the emerging Asian factor are similar to the baseline results presented in Section 3, while the results change when we use the emerging South American factor, see figures 7 and 8 in Appendix C. In particular, the emerging South 
American factor explains slightly less of the variance in oil prices and almost half of the variance in oil production compared to the results in Figure 4. Therefore, we again confirm that Asia is the primary driver of the emerging factor, but the role of South America is far from negligible. ${ }^{16}$

Furthermore, our main results are not particularly sensitive to the number of lags used in the transition equation. In fact, when we estimate the model with two lags instead of four, the results are slightly stronger, implying that the emerging factor explains an even larger share of oil prices and oil production. Moreover, as mentioned in Section 2.3.1, the factor estimates are not significantly affected by the choice of normalizing variables or to the estimation method.

As described in Section 2.3.2, an advantage of our identification strategy is that we can identify distinct demand shocks that affect both the developed and the emerging factors simultaneously. If simultaneity were unimportant, however, then the FAVAR model could be identified using a standard recursive identification strategy, ordering the developed factor above the emerging factor or vice versa. Identifying such a recursive model, however, yields as expected, very different results from our baseline model. In particular, now the activity factor ordered first will always explain more of the variation in the oil price than the activity factor ordered second. Thus, simultaneity matters, which a standard recursive identification strategy does not adequately capture. Despite this, recursive identification strategies nonetheless reveal that the emerging factor plays an important role. First, the emerging activity factor will always explain relatively more of the variation in the oil price than the developed factor, irrespective of where it is ordered. ${ }^{17}$ Second, emerging countries always explain more of the variance in oil production than developed economies, independent of the ordering of the emerging and the developed factors.

Finally, neither the frequentist nor the Bayesian theory is conclusive on how confidence bands should be presented when structural disturbances are generated from sign restrictions. Moon et al. (2011) analyze the problem for classical VARs, in a frequentist setting. This do not apply directly to us,

\footnotetext{
${ }^{16}$ We have also tried to approximate developed and emerging activity with observable GDP growth in the US and China. In this model demand shocks from the US and China together accounts for about 25-30 percent of the variation in the real price of oil. However, the impulse responses from this model are not consistent with theory and earlier research. This is not surprising. GDP is measured with substantial noise and errors, and developed and emerging activity is not only driven by the US and China.

${ }^{17}$ When the emerging factor is ordered first, it explains nearly twice as much of the variation in oil prices than when the developed factor is ordered first. Similarly, when the emerging factor is ordered last, it explains more than twice as much of the variation in oil prices than the developed factor does when ordered last.
} 
as we estimate a FAVAR where uncertainty in both parameter and factor estimates should be taken into account. Further, the sign restrictions we employ are not those that are studied in Moon et al. (2011). In Appendix E we show that our results are robust to alternative estimation strategies (i.e. Bayesian). We also document how the uncertainty bands reported in figure 3 are only partially affected by the fact that some of the shocks in the model are set identified (i.e. sign identified).

\section{Conclusion}

We estimate a FAVAR model with separate activity factors for emerging and developed economies in addition to global oil production and the real price of oil. We study two main questions: 1) How demand shocks in emerging and developed economies affect the real price of oil and global oil production, and 2) the effects of oil supply and oil-specific demand shocks on emerging and developed economies. To our knowledge, this is the first paper to explicitly analyze the contribution of developed and emerging countries on oil market variables (and vice versa) using a structural model. We have three main findings that are robust to numerous robustness checks.

First, we demonstrate that demand shocks to emerging and developed economies account for 50-60 percent of the fluctuations in the real price of oil over the last two decades. Second, demand shocks to emerging markets, and in Asia in particular, are far more important than demand shocks in developed economies in explaining fluctuations in the real price of oil and in global oil production. This is a new finding in the literature.

Finally, we find that different regions respond differently to adverse oil market shocks. While economic activity in Europe and the US is permanently reduced following oil supply and oil-specific demand shocks, economic activity in emerging countries in Asia and South America falls by much less, and in some cases actually increases temporarily (at least following oil supply shocks). While some of these results relate to the fact that many emerging countries are commodity exporters that benefit from higher terms of trade, we also find that countries with high investment shares in GDP and high degrees of openness are less negatively affected by higher oil prices.

Our results suggest that it is imperative not only to identify where demand for energy is coming from, but also to allow countries/regions to respond differently to various oil market shocks. Hence, the common practice today of using a global activity index like that constructed in Kilian (2009) to analyse the oil market, while useful in capturing the large role of demand for oil prices, will underestimate any negative effects an adverse oil price 
shock can have on countries that respond differently from the main drivers of oil demand (i.e. developed versus emerging countries). For policy makers, knowledge of this interdependence is important.

\section{References}

Aastveit, K. A. (2013). Oil price shocks and monetary policy in a data-rich environment. Working Paper 2013/10, Norges Bank.

Aastveit, K. A., H. C. Bjørnland, and L. A. Thorsrud (2011). The world is not enough! Small open economies and regional dependence. Working Paper 2011/16, Norges Bank.

Bai, J. and S. Ng (2002). Determining the number of factors in approximate factor models. Econometrica $70(1), 191-221$.

Bai, J. and S. Ng (2006). Confidence intervals for diffusion index forecasts and inference for factor-augmented regressions. Econometrica 74 (4), 11331150.

Bai, J. and S. Ng (2013). Principal components estimation and identifiaction of static factors. Journal of Econometrics, Forthcoming.

Barsky, R. B. and L. Kilian (2002). Do we really know that oil caused the great stagflation? a monetary alternative. In B. S. Bernanke and K. Rogoff (Eds.), NBER Macroeconomics Annual 2001, pp. 137-183. MIT Press: Cambridge, MA.

Barsky, R. B. and L. Kilian (2004). Oil and the macroeconomy since the 1970s. Journal of Economic Perspectives 18(4), 115-134.

Baumeister, C. and G. Peersman (2012). The role of time-varying price elasticities in accounting for volatility changes in the crude oil market. Journal of Applied Econometrics, Forthcoming.

Baumeister, C. and G. Peersman (2013). Time-varying effects of oil supply shocks on the U.S. economy. American Economic Journal: Macroeconomics, Forthcoming.

Bernanke, B., J. Boivin, and P. S. Eliasz (2005). Measuring the effects of monetary policy: A factor-augmented vector autoregressive (FAVAR) approach. Quarterly Journal of Economics 120(1), 387-422. 
Bjørnland, H. C. (1998). The economic effects of North Sea oil on the manufacturing sector. Scottish Journal of Political Economy 45(5), 553-85.

Bjørnland, H. C. (2000). The dynamic effects of aggregate demand, supply and oil price shocks - A comparative study. Manchester School of Economic Studies 68(5), 578-607.

Blanchard, O. J. and J. Galí (2010). The macroeconomic effects of oil price shocks: Why are the 2000s so different from the 1970s? In J. Gali and M. Gertler (Eds.), International Dimensions of Monetary Policy, pp. 373428. University of Chicago Press: Chicago, IL.

Boivin, J., M. P. Giannoni, and I. Mihov (2009). Sticky prices and monetary policy: Evidence from disaggregated US data. American Economic Review 99(1), 350-84.

Boivin, J., M. P. Giannoni, and B. Mojon (2009). How has the Euro changed the monetary transmission? In D. Acemoglu, K. Rogoff, and M. Woodford (Eds.), NBER Macroeconomics Annual 2008, pp. 77-125. University of Chicago Press: Chicago, IL.

Burbidge, J. and A. Harrison (1984). Testing for the effects of oil-price rises using vector autoregressions. International Economic Review 25(2), 45984.

Edelstein, P. and L. Kilian (2009). How sensitive are consumer expenditures to retail energy prices? Journal of Monetary Economics 56(6), 766-779.

Eickmeier, S., W. Lemke, and M. Marcellino (2011). The changing international transmission of financial shocks: Evidence from a classical timevarying FAVAR. CEPR Discussion Papers 8341.

Eickmeier, S. and T. Ng (2011). How do credit supply shocks propagate internationally? A GVAR approach. CEPR Discussion Papers 8720.

Farrant, K. and G. Peersman (2006). Is the exchange rate a shock absorber or a source of shocks? New empirical evidence. Journal of Money, Credit and Banking 38(4), 939-961.

Fry, R. and A. Pagan (2011). Sign restrictions in structural vector autoregressions: A critical review. Journal of Economic Literature 49(4), 938-60.

Gisser, M. and T. H. Goodwin (1986). Crude oil and the macroeconomy: Tests of some popular notions: A note. Journal of Money, Credit and Banking 18(1), 95-103. 
Goncalves, S. and B. Perron (2013). Bootstrapping factor-augmented regression models. Journal of Econometrics, Forthcoming.

Hall, P. (1992). The bootstrap and Edgeworth expansion. Springer: New York, NY.

Hamilton, J. D. (1983). Oil and the macroeconomy since world war II. Journal of Political Economy 91(2), 228-248.

Hamilton, J. D. (1996). This is what happened to the oil price-macroeconomy relationship. Journal of Monetary Economics 38(2), 215-220.

Hamilton, J. D. (2003). What is an oil shock? Journal of Econometrics 113(2), 363-398.

Hamilton, J. D. (2009). Causes and consequences of the oil shock of 2007-08. Brookings Papers on Economic Activity 40(1), 215-283.

Hamilton, J. D. (2013). Historical oil shocks. In R. E. Parker and R. M. Whaples (Eds.), Routledge Handbook of Major Events in Economic History, pp. 239-265. New York: Routledge Taylor and Francis Group.

Hamilton, J. D. and A. M. Herrera (2004). Oil Shocks and Aggregate Macroeconomic Behavior: The Role of Monetary Policy: Comment. Journal of Money, Credit and Banking 36(2), 265-86.

Herrera, A. M., L. G. Lagalo, and T. Wada (2012). Asymmetries in the oil price-industrial production relationship? Evidence from 18 OECD countries. Mimeo, Wayne State University.

Hicks, B. and L. Kilian (2012). Did unexpectedly strong economic growth cause the oil price shock of 2003-2008? Journal of Forecasting, Forthcoming.

Kilian, L. (2009). Not all oil price shocks are alike: Disentangling demand and supply shocks in the crude oil market. American Economic Review 99(3), 1053-1069.

Kilian, L. and D. Murphy (2013). The role of inventories and speculative trading in the global market for crude oil. Journal of Applied Econometrics, Forthcoming.

Kilian, L. and C. Park (2009). The impact of oil price shocks on the u.s. stock market. International Economic Review 50(4), 1267-1287. 
Kilian, L., A. Rebucci, and N. Spatafora (2009). Oil shocks and external balances. Journal of International Economics 777(2), 181-194.

Lippi, F. and A. Nobili (2012). Oil and the macroeconomy: A quantitative structural analysis. Journal of the European Economic Association 10(5), $1059-1083$.

Moon, H. R., F. Schorfheide, E. Granziera, and M. Lee (2011). Inference for vars identified with sign restrictions. Working Papers 11-20, Federal Reserve Bank of Philadelphia.

Mumtaz, H. and P. Surico (2009). The transmission of international shocks: A factor-augmented VAR approach. Journal of Money, Credit and Banking 41(s1), 71-100.

Peersman, G. and I. Van Robays (2012). Cross-country differences in the effects of oil shocks. Energy Economics 34 (5), 1532-1547.

Pesaran, M. H., T. Schuermann, and L. V. Smith (2009). Rejoinder to comments on forecasting economic and financial variables with global VARs. International Journal of Forecasting 25(4), 703-715.

Rubio-Ramirez, J. F., D. F. Waggoner, and T. Zha (2010). Structural vector autoregressions: Theory of identification and algorithms for inference. Review of Economic Studies 77(2), 665-696.

Stock, J. H. and M. W. Watson (2002). Macroeconomic forecasting using diffusion indexes. Journal of Business 85 Economic Statistics 20(2), 147162.

Thorsrud, L. A. (2013). Global and regional business cycles. shocks and propagations. Working Paper 2013/08, Norges Bank. 


\section{Appendices}

\section{Appendix A Data and Sources}

Most of the data series are collected from Ecowin. The few series we did not find there, were taken from the following sources: Gross Domestic Product (GDP) in China and Indonesia were found in the GVAR data set constructed by Pesaran et al. (2009). The series for industrial production (IP) in Argentina, Indonesia, Mexico and the Netherlands were collected from Datastream. The industrial production series in Denmark and Portugal were taken from OECD, while industrial production in Norway was collected from Statistics Norway.

All GDP series are at constant prices. The industrial production series are volume indexes, and refer, with few exceptions, to the manufacturing industry. For Argentina, China, Indonesia, Italy, Norway, Peru and Portugal, we only found series for overall industrial production.

Lastly, some of the activity series do not span the whole time period used in the analysis (1991:Q1 to 2009:Q4). To avoid excluding these variables from the sample, we have applied the EM algorithm, as described in Stock and Watson (2002), to construct the missing observations. However, experiments conducted on a reduced sample, i.e. excluding the series with missing observations, do not change our main conclusions. 


\section{Appendix B Tables}

Table 2: Oil production and consumption by countries

\begin{tabular}{|c|c|c|c|c|}
\hline & Country & Production & Consumption & Net exporter \\
\hline \multirow[t]{18}{*}{ Developed } & Australia & 0.64 & 0.87 & No \\
\hline & Belgium & 0.01 & 0.61 & No \\
\hline & Canada & 2.83 & 2.03 & Yes \\
\hline & Denmark & 0.29 & 0.20 & Yes \\
\hline & Finland & 0.01 & 0.21 & No \\
\hline & France & 0.09 & 1.97 & No \\
\hline & Germany & 0.13 & 2.74 & No \\
\hline & Italy & 0.14 & 1.83 & No \\
\hline & Japan & 0.11 & 5.36 & No \\
\hline & Netherlands & 0.06 & 0.89 & No \\
\hline & New Zealand & 0.05 & 0.14 & No \\
\hline & Norway & 2.93 & 0.22 & Yes \\
\hline & Portugal & 0.00 & 0.31 & No \\
\hline & Spain & 0.03 & 1.39 & No \\
\hline & Sweden & 0.00 & 0.37 & No \\
\hline & Switzerland & 0.00 & 0.27 & No \\
\hline & United Kingdom & 2.32 & 1.78 & Yes \\
\hline & United States & 9.04 & 19.19 & No \\
\hline \multirow[t]{15}{*}{ Emerging } & Argentina & 0.80 & 0.50 & Yes \\
\hline & Brazil & 1.59 & 2.06 & No \\
\hline & Chile & 0.02 & 0.23 & No \\
\hline & China & 3.45 & 5.17 & No \\
\hline & Hong Kong & 0.00 & 0.25 & No \\
\hline & India & 0.77 & 2.12 & No \\
\hline & Indonesia & 1.38 & 1.04 & Yes \\
\hline & Korea, South & 0.01 & 2.06 & No \\
\hline & Malaysia & 0.75 & 0.46 & Yes \\
\hline & Мexico & 3.42 & 2.00 & Yes \\
\hline & Peru & 0.11 & 0.15 & No \\
\hline & Singapore & 0.01 & 0.69 & No \\
\hline & South Africa & 0.20 & 0.47 & No \\
\hline & Taiwan & 0.00 & 0.83 & No \\
\hline & Thailand & 0.21 & 0.77 & No \\
\hline
\end{tabular}

Note: Column three to five reports oil production and oil consumption in millions of barrels per day, measured as averages for the period 1992-2009 (Source: EIA). 
Table 3: Correlation with factors

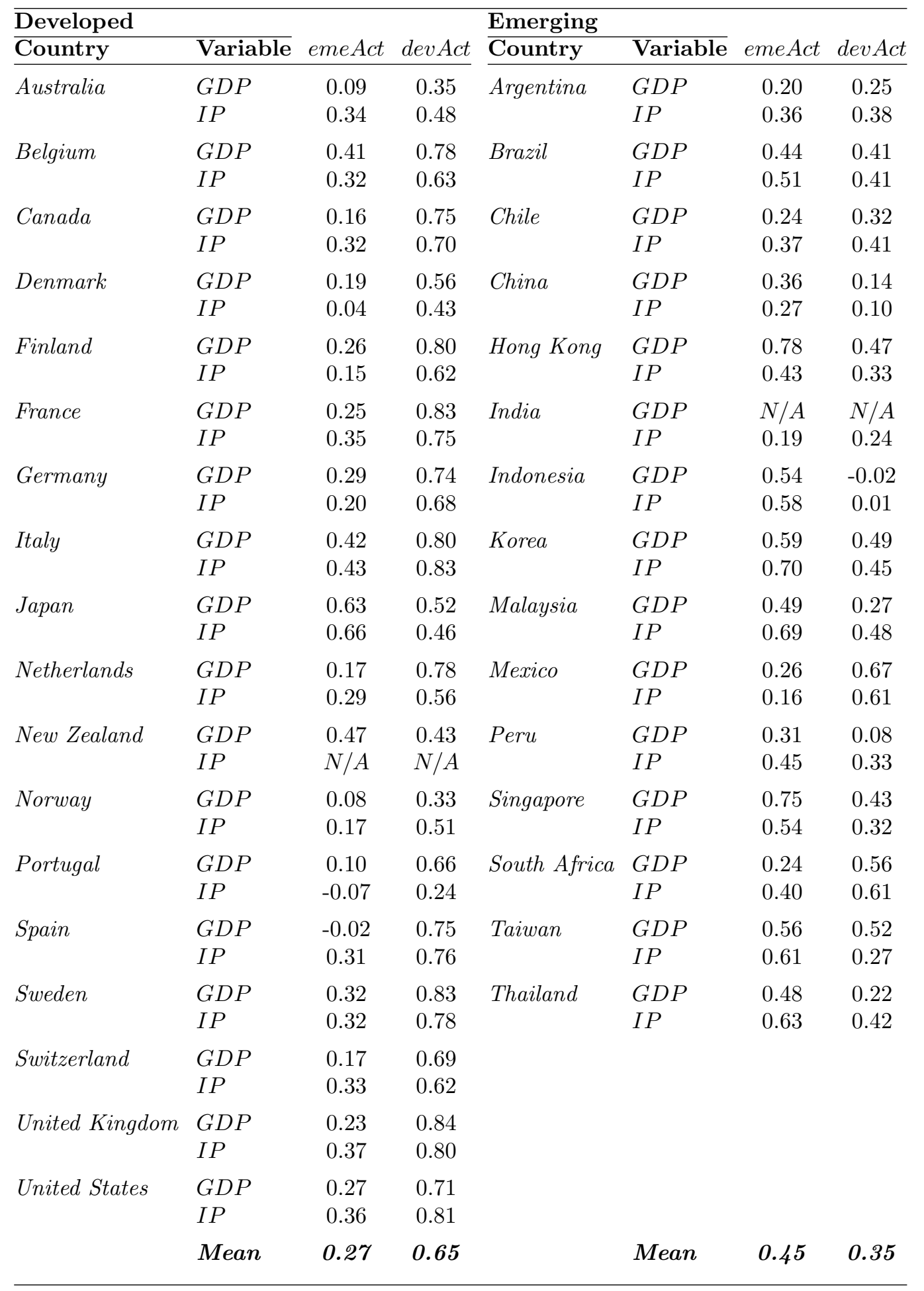

Note: Column three to four, and seven to eight report the correlation between observable activity variables and the identified emerging and developed activity factors. IP is an abbreviation for industrial production. $N / A$ are missing values. 


\section{Appendix C Figures}

\section{Figure 7: Variance decomposition: Asia only}

(a) Oil price

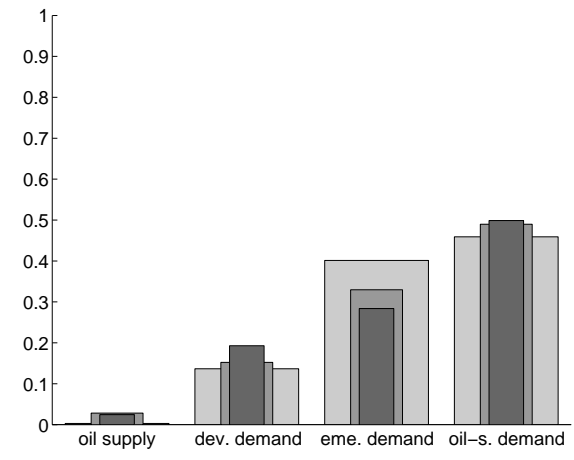

(b) Oil production

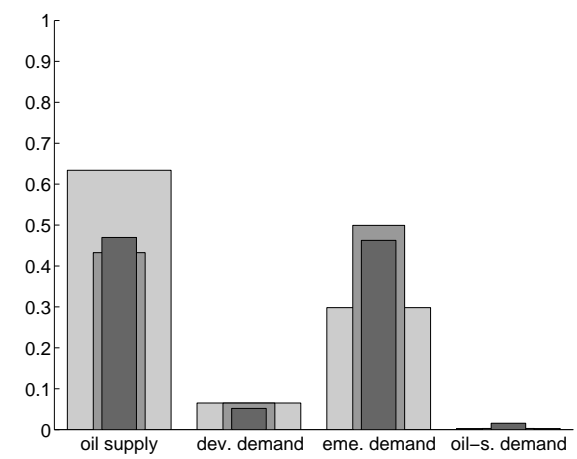

Note: The bars display the variance decomposition with respect to the shocks for horizons 4, 8 and 12 quarters. The widest bars correspond to the shorter horizon.

\section{Figure 8: Variance decomposition: South America only}

(a) Oil price

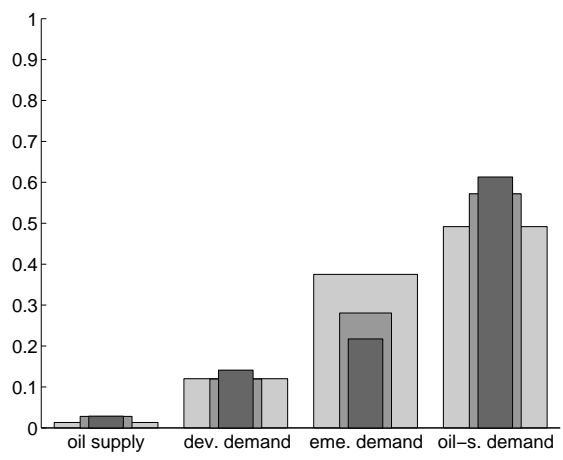

(b) Oil production

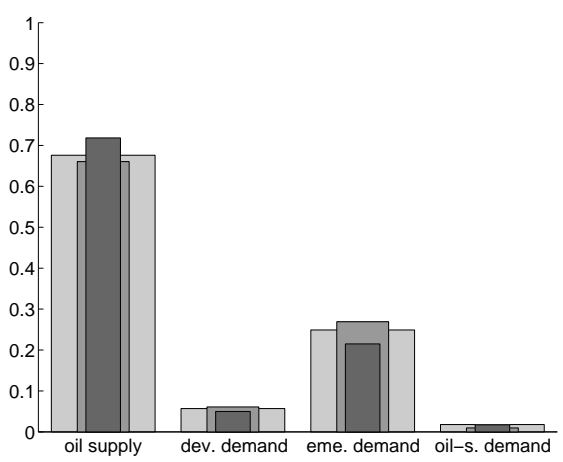

Note: The bars display the variance decomposition with respect to the shocks for horizons 4, 8 and 12 quarters. The widest bars correspond to the shorter horizon. 
Figure 9: Impulse responses: Oil supply shock

Australia

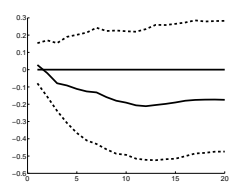

France

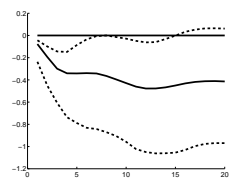

New Zealand

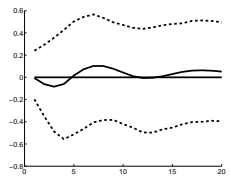

Switzerland

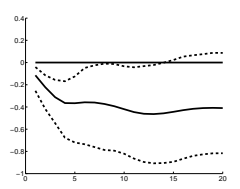

Argentina

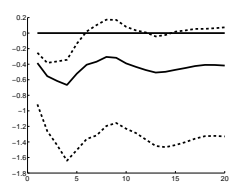

India

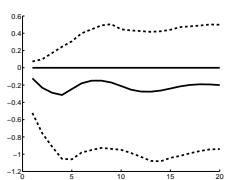

Peru

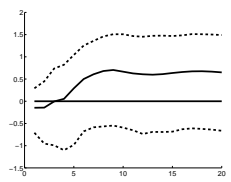

Belgium

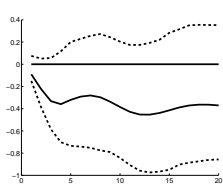

Germany

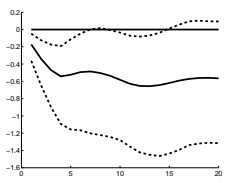

Norway

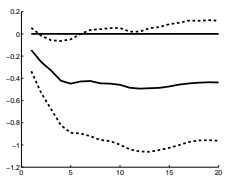

UK

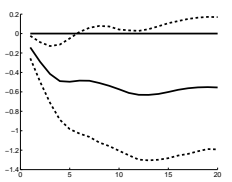

Brazil

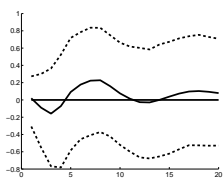

Indonesia

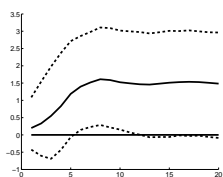

Singapore

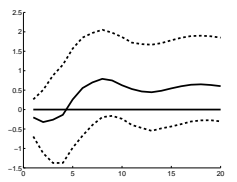

Canada

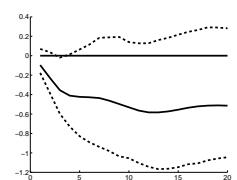

Italy

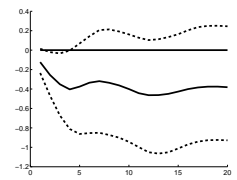

Portugal

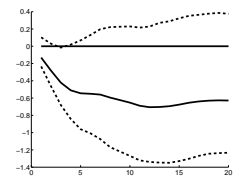

US

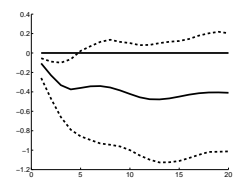

Chile

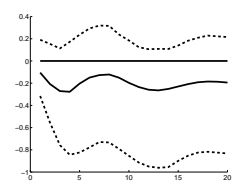

Korea

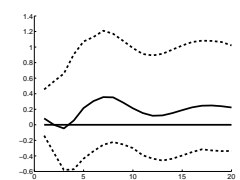

South Africa

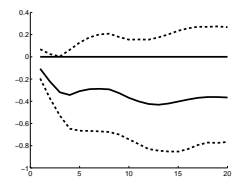

Denmark

Finland

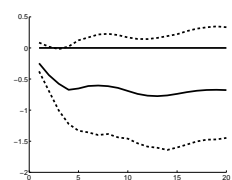

Japan

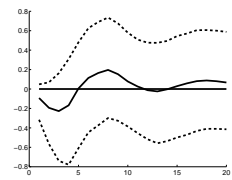

Spain
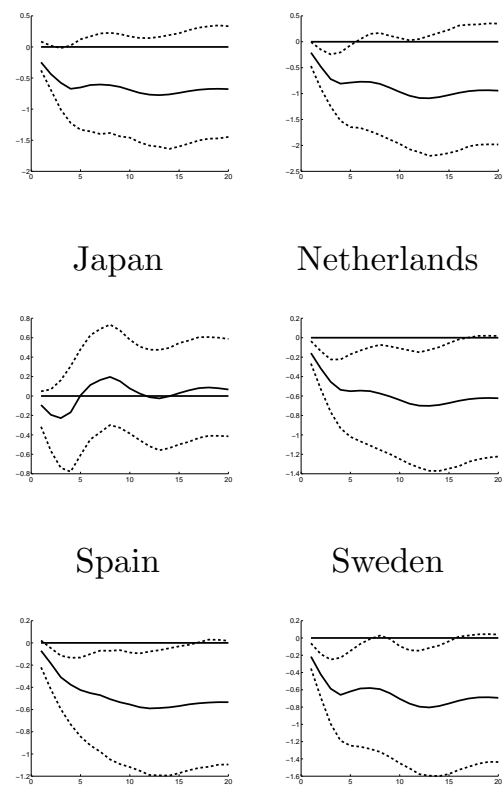

Netherlands

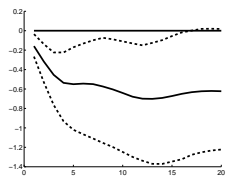

Sweden

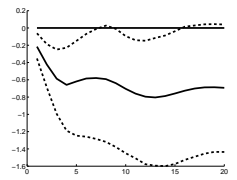

Hong Kong

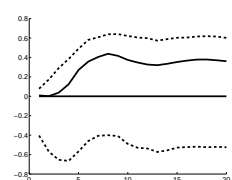

Malaysia

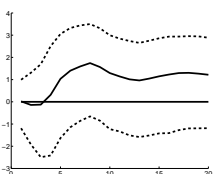

Taiwan

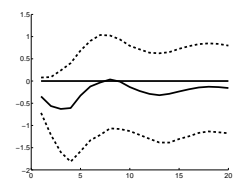

Mexico
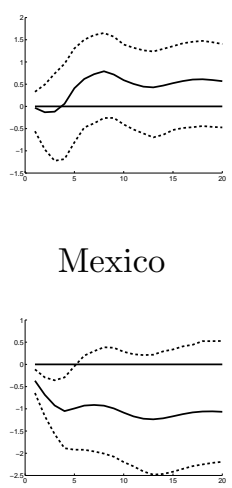

Thailand

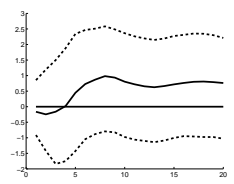

Note: The figures show the responses of GDP (in percent) in a given country after a normalized oil supply shock (see Notes to Figure 3 for further details). 
Figure 10: Impulse responses: Oil-specific demand shock

Australia

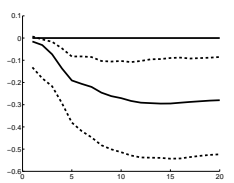

France

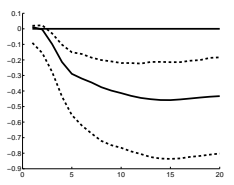

New Zealand

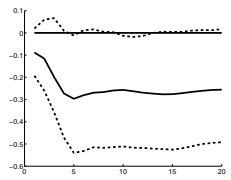

Switzerland

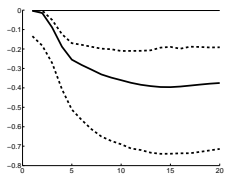

Argentina

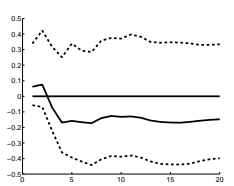

India

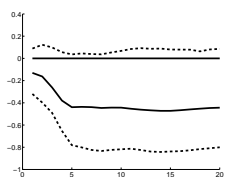

Peru

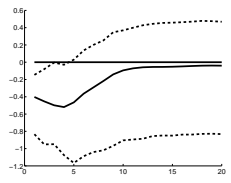

Belgium

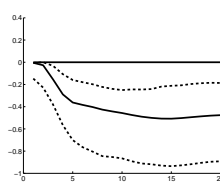

Germany

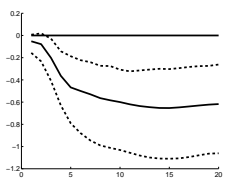

Norway

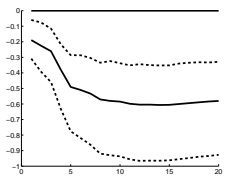

UK

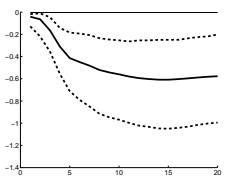

Brazil

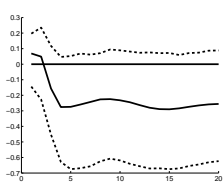

Indonesia

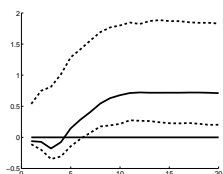

Singapore

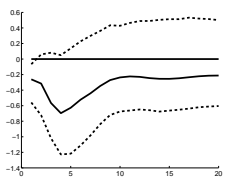

Canada

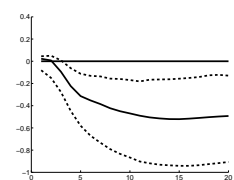

Italy

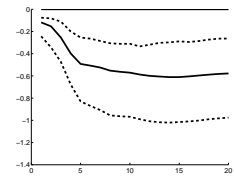

Portugal

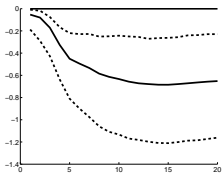

US

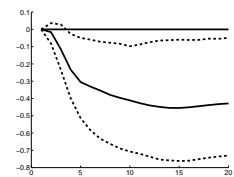

Chile

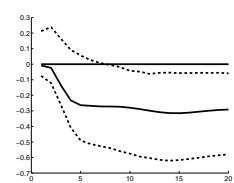

Korea

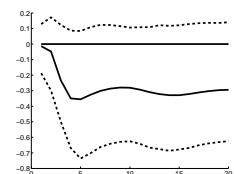

South Africa

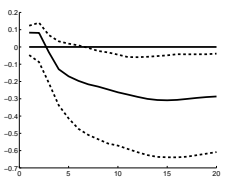

Denmark

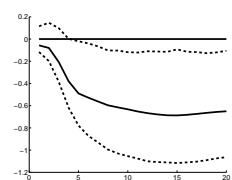

Japan

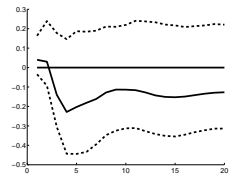

Spain

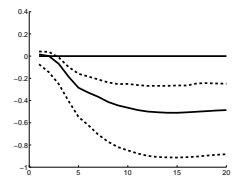

Netherlands

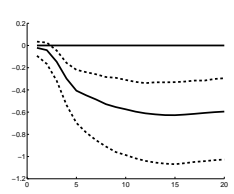

Sweden
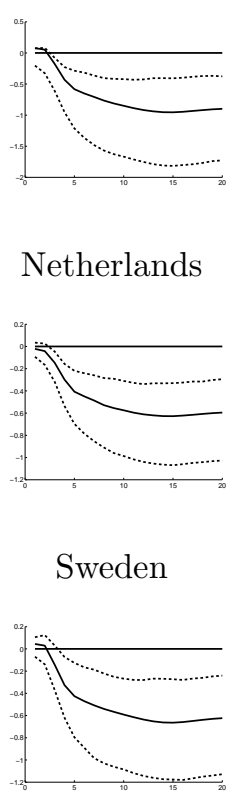

Hong Kong
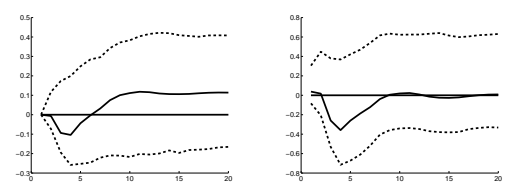

Mexico

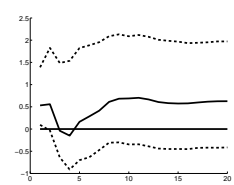

Taiwan

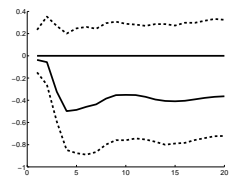

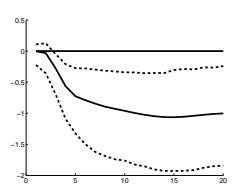

Thailand

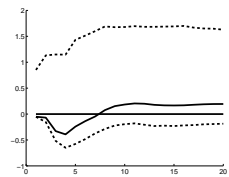

Note: The figures show the responses of GDP (in percent) in a given country after a oilspecific demand shock that increases oil prices with 10 percent (see Notes to Figure 3 for further details). 
Figure 11: Regression of oil shocks on observable GDP

(a) Oil supply

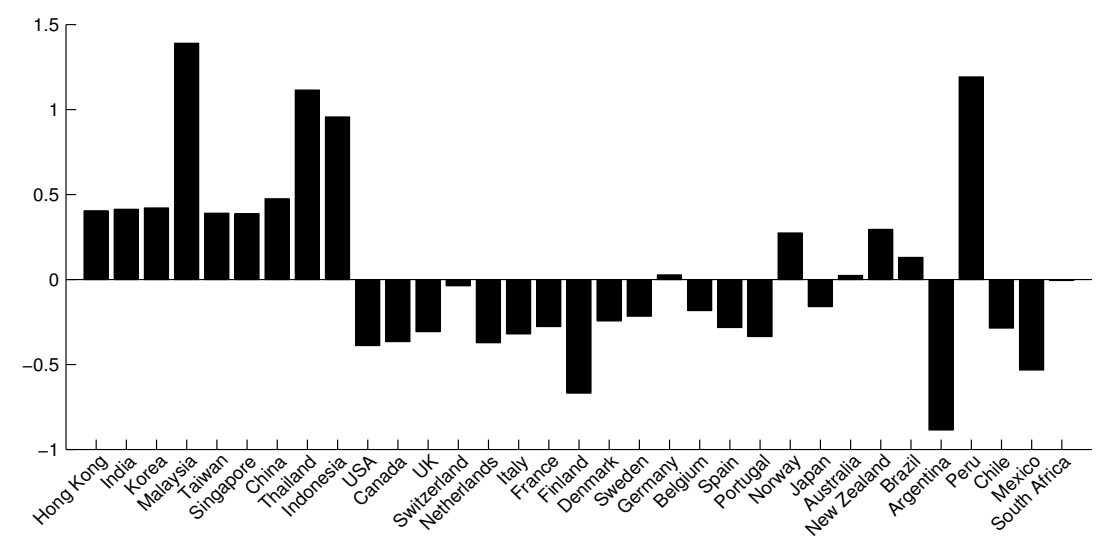

(b) Oil-specific demand

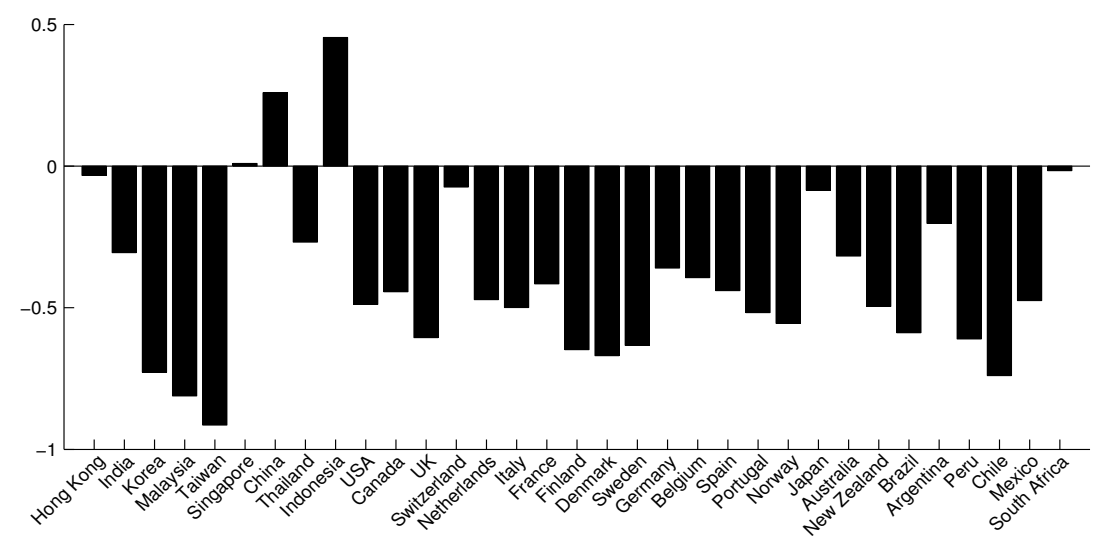

Note: The bars show for each country the accumulated regression coefficients from the following regressions:

$$
\Delta X_{t, i}=\alpha_{i}+\sum_{p=1}^{4} \beta_{p, i} s_{t-p}+e_{t, i}
$$

where $\Delta X_{t, i}$ is the observable GDP growth in country $i$ at time $t, \alpha$ and $\beta$ are coefficients, and $s_{t-p}$ are lags of the structural shocks (oil supply or oil-specific demand) identified in our model. 


\section{Appendix D Implementation of sign restric- tions}

We implement the following algorithm for each draw of the reduced form covariance matrix $\Omega$ :

1. Let $\Omega=P P^{\prime}$ be the Cholesky decomposition of the VAR covariance matrix $\Omega$, and $\tilde{A}_{0}=P$.

2. Draw an independent standard normal $\mathrm{n} \mathrm{x} \mathrm{k}$ matrix $\mathrm{J}$, where $\mathrm{n}$ is the size of the block (e.g. developed and emerging) and $\mathrm{k}$ is the number of shocks affecting that block according to the block exogenous structure outlined in section 2.3 and equation 4 . Let $J=Q R$ be the "economy size" QR decomposition of $\mathrm{J}$ with the diagonal of $\mathrm{R}$ normalized to be positive.

3. Compute a candidate structural impact matrix $A_{0}=\tilde{A}_{0} \cdot \tilde{Q}$, where $\tilde{Q}$ is a $\mathrm{N} \times \mathrm{N}$ identity matrix with $Q^{\prime}$ in the $\mathrm{n} \times \mathrm{k}$ block associated with the developed and emerging block in equation 4 .

4. Redo step 1-3 for the next block of data.

If the candidate matrix satisfies the sign restrictions, we keep it. Otherwise the procedure above is repeated. The imposed signs can also be restricted to hold for many periods, in which case the candidate matrix must be past into the impulse response function before validation.

\section{Appendix E Set identification and alternative estimation strategies}

Generally, our sign restrictions are very informative, meaning that the set of admissible impulse responses is rather narrow. This is illustrated in figure 12. The figure reports the set of admissible impulse responses for 5000 draws based on the point estimates of $\beta$ and $\Sigma$.

Importantly, variance decompositions of the set of impulse responses reported in figure 12 are highly conclusive and supportive of the results already reported. Demand shocks originating in developed economies never explain more than 0.15 percent of the variation in global oil production. At horizons exceeding 5 quarters ahead, demand shocks originating in emerging economies never explain less than around 40 percent of the same variation. Further, for horizons up to 12 quarters ahead, demand shocks originating in 
emerging economies are almost unambiguously more important than demand shocks originating in developed economies in explaining the variation in the real price of oil. For example, at horizon 4, the set of variance decompositions attributed to emerging demand is in the range 20 to 60 percent, while the same range for developed demand is 0.02 to 30 percent.

We stress that for a particular (bootstrapped) parameter set, $\beta$ and $\Sigma$, any draw of the sign-restricted structural disturbances will not cause the impulse responses in columns one and four in figure 3 to change. Only impulse responses in columns two and three are affected. Thus, these are set identified, while the former are point identified. I.e. in figure 3 , the confidence bands reported in columns one and four are purely a function of parameter uncertainty.

We have also estimated the model outlined in section 2.1 using a Bayesian Dynamic Factor Model (BDFM) specification. As shown in figure 13, the impulse responses and the uncertainty estimates from the BDFM are very similar to the once presented in figure 3.

In this application we still prefer the FAVAR specification because of its simplicity. I.e. estimating, identifying and simulating the FAVAR model requires only a few lines of Matlab code and takes less than 120 seconds. On the other hand, the BDFM is much more code and time consuming to solve. Further, the distributional assumptions (on e.g. $u$ and $e$ ) which underline the simulations done to solve the BDFM are much more restrictive than in our FAVAR case (where the simulation is non-parametric). 
Figure 12: Impulse responses: Point estimates and admissible sets

Shocks

Oil supply

Developed demand Emerging demand Oil-specific demand
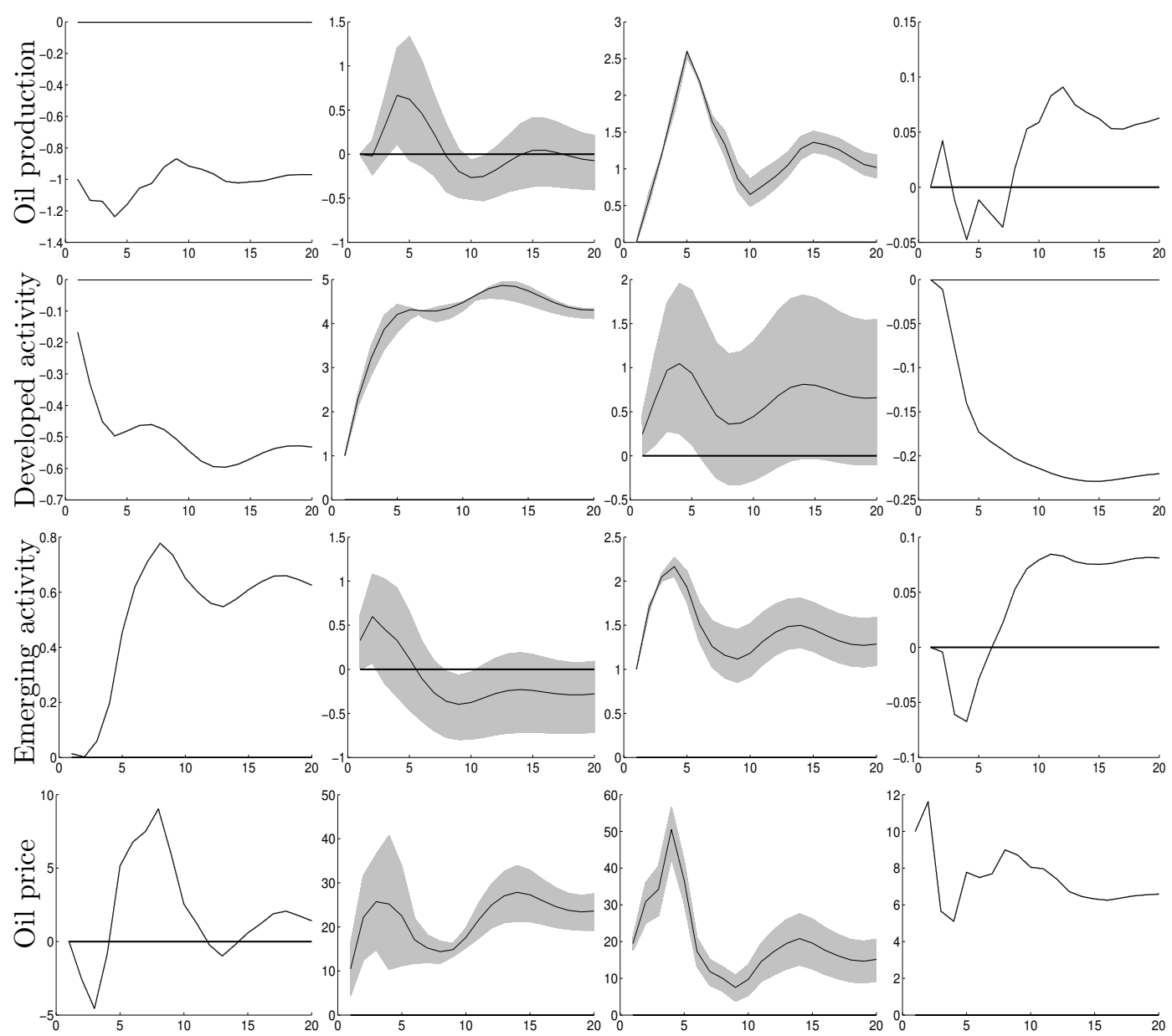

Note: See the text and figure 3 for details. 


\section{Figure 13: Impulse responses: Bayesian estimates}

\section{Shocks}

Oil supply

Developed demand Emerging demand Oil-specific demand
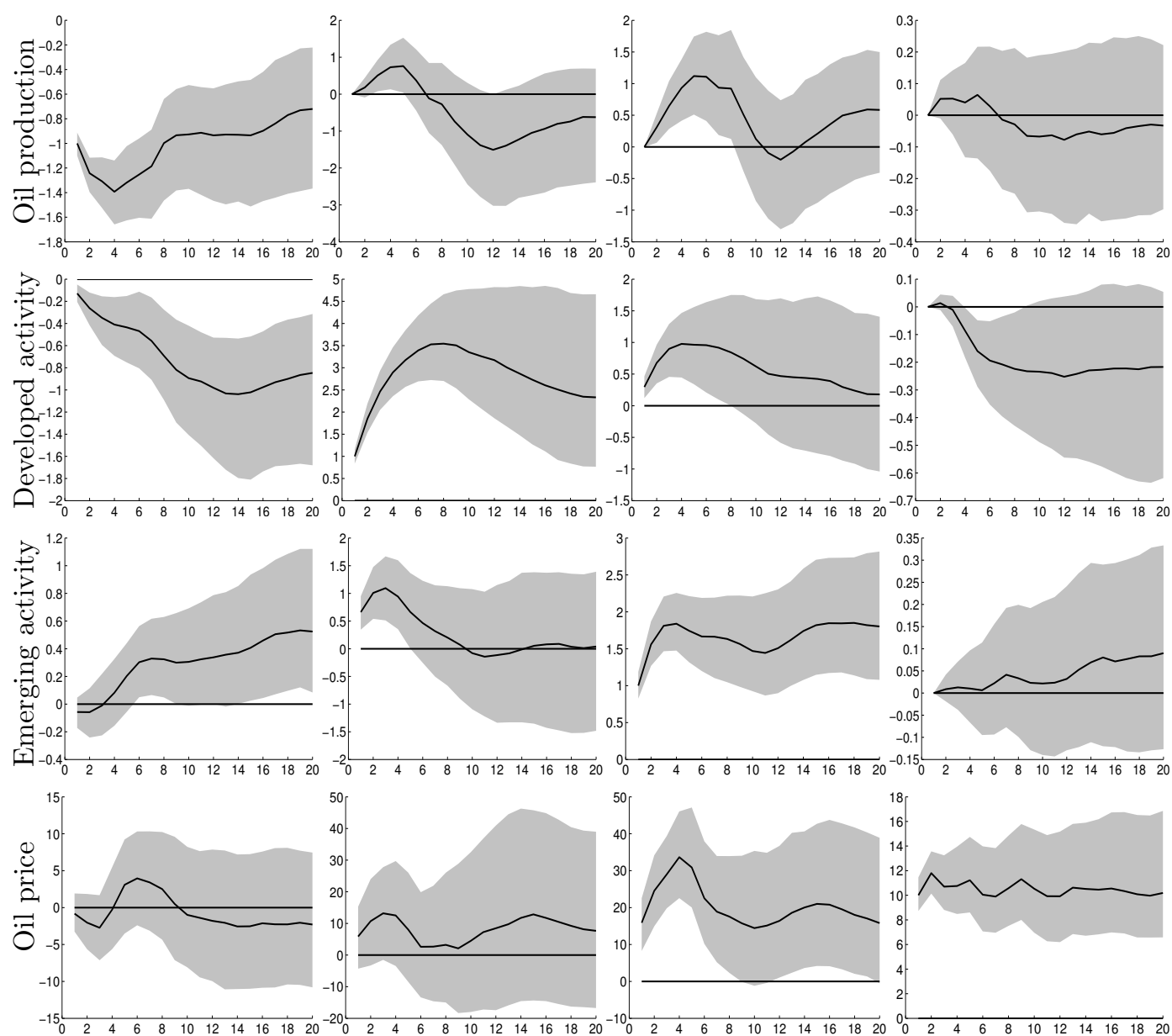

Note: See the text and figure 3 for details. 
Centre for Applied Macro - and Petroleum economics (CAMP)

will bring together economists working on applied macroeconomic issues, with special emphasis on petroleum economics.

BI Norwegian Business School

Centre for Applied Macro - Petroleum economics (CAMP)

$\mathrm{N}-0442$ Oslo

http://www.bi.edu/camp 